\title{
Design and Analyses of High Aspect Ratio Nozzles for Distributed Propulsion Acoustic Measurements
}

\author{
Vance F. Dippold, III \\ NASA Glenn Research Center, Cleveland, Ohio 44135
}

\begin{abstract}
A series of three convergent, round-to-rectangular high aspect ratio (HAR) nozzles were designed for acoustic testing at the NASA Glenn Research Center Nozzle Acoustic Test Rig (NATR). The HAR nozzles had exit area aspect ratios of 8:1, 12:1, and 16:1. The nozzles were designed to mimic a distributed propulsion system array with a slot nozzle. The nozzle designs were screened using Reynolds-Averaged NavierStokes (RANS) simulations. In addition to meeting the geometric constraints required for testing in the NATR, the HAR nozzles were designed to be free of flow features that would produce unwanted noise (e.g., flow separations) and to have uniform flow at the nozzle exit. Multiple methods were used to generate HAR nozzle designs. The final HAR nozzle designs were generated in segments using a computer code that parameterized each segment. RANS screening simulations showed that intermediate nozzle designs suffered flow separation, a normal shockwave at the nozzle exit (caused by an aerodynamic throat produced by boundary layer growth), and nonuniform flow at the nozzle exit. The RANS simulations showed that the final HAR nozzle designs were free of flow separations, but were not entirely successful at producing a fully uniform flow at the nozzle exit. The final designs suffered a pair of counter-rotating vortices along the outboard walls of the nozzle. The 16:1 aspect ratio HAR nozzle had the least uniform flow at the exit plane; the 8:1 aspect ratio HAR nozzles had a fairly uniform flow at the nozzle exit plane.
\end{abstract}

Nomenclature

$\begin{array}{ll}A_{j e t} & =\text { Nozzle exit area } \\ C_{d} & =\text { Discharge coefficient } \\ C_{V} & =\text { Thrust coefficient } \\ D_{e q} & =\text { Equivalent diameter of nozzle exit; equal to diameter of round nozzle of equivalent exit area } \\ M_{j e t} & =\text { Mach number for ideally-expanded jet } \\ p & =\text { Local static pressure } \\ p_{0} & =\text { Nozzle total pressure } \\ p_{\infty} & =\text { Freestream static pressure } \\ u, v, w & =\text { Components of velocity in the } x-, y-, \text { and } z \text {-directions } \\ U_{j e t} & =\text { Velocity for ideally-expanded jet } \\ W & =\text { Vorticity magnitude } \\ x, y, z & =\text { Orthogonal coordinate system } \\ y^{+} & =\text {Non-dimensional wall distance } \\ \rho & =\text { Density }\end{array}$

\section{Introduction}

It is generally presumed that future transport aircraft must depart from the conventional "tubeand-wing" configuration if they are to significantly advance beyond present-day performance achievements. NASA's roadmap for future revolutionary aircraft includes a hybrid-wing-body concept that is powered by a turboelectric distributed propulsion system ${ }^{1,2}$, pictured in Figure 1 . This distributed

\footnotetext{
* Aerospace Engineer, Inlets and Nozzles Branch, 21000 Brookpark Rd, and AIAA Senior Member
} 
propulsion arrangement is a significant departure from present technology in several ways: the power source consists of wing-tip mounted turboelectric generators, rather than fuselage-mounted or underwing turbofans; an array of electric-powered fans distributes the propulsion across a significant span of the aircraft, rather than propulsion found at two to four points as with conventional engines; and the fan nozzles exhaust over the aircraft's aft deck surface, giving the opportunity for jet-and-surface interactions, rather than the jet streams exhausting from isolated points away from wing and fuselage surfaces. Jet noise from this distributed propulsion system configuration has yet to be fully explored.

The Jet-Surface Interaction-High Aspect Ratio (JSI-HAR) nozzle tests were conducted at the NASA Glenn Research Center to explore the acoustic performance of the jet plume of an array of distributed propulsion system nozzles interacting with a surface ${ }^{3}$. The array of distributed nozzles was represented by a single rectangular high aspect ratio (HAR) nozzle containing internal septa near the nozzle exit. The Nozzle Acoustic Test Rig (NATR), which has a round inflow for use with conventional circular nozzles, was used for this series of tests because of its large scale (compared to other available jet acoustics facilities) and its ability to operate with a co-annual free-jet to simulate flight. This paper will discuss the design and performance analysis of round-to-rectangular high aspect ratio nozzles with exit aspect ratios of 16:1, 12:1, and 8:1 for the JSI-HAR nozzle experiment.

\section{Nozzle Design Requirements}

Three convergent round-to-rectangular high aspect ratio (HAR) nozzles were designed for acoustic measurements on the NASA Glenn Research Center Nozzle Acoustic Test Rig (NATR). The nozzles had exit aspect ratios of 16:1, 12:1, and 8:1. The inflow of each nozzle was circular, with a diameter of 10.29 inches, allowing the nozzles to attach directly to the NATR. The nozzle exit area was dictated by the largest mass flow that could flow through the NATR for a jet Mach number of 0.98 (equivalent to an acoustic Mach number of 0.9). The outflow dimensions of each the nozzle is specified in Table 1 . In this study, the equivalent diameter, $D_{e q}$, is defined as:

$$
D_{e q}=2 \cdot \sqrt{\left(\frac{1}{\pi}\right) \cdot A_{j e t}}=2 \cdot \sqrt{\left(\frac{1}{\pi}\right) \cdot \text { Height } \cdot \text { Width }}
$$

A number of other requirements guided the design of the HAR nozzles:

- The nozzles needed to be no longer than approximately 24 inches. This ensured that the HAR nozzles' jet plumes would be contained within the NATR's free-jet potential core (when simulating flight). This requirement would also help reduce nozzle weight and the weight load supported by the NATR.

- Unfavorable flow characteristics, such as internal flow separations and exit shocks, would need to be minimized, as they would likely produce unwanted noise. Since the nozzles were being designed for acoustic measurements, it was vital that rig noise be minimized.

- The HAR nozzles needed to have a segment of constant spanwise width near the nozzle exit to accommodate the septa inserts. The internal septa inserts - rapid-prototyped plastic inserts would be placed inside the HAR nozzles to mimic the flow from multiple nozzles in a distributed propulsion arrangement.

- The flow going into the septa insert segment would need to be nearly uniform. This would best represent the flow through individual propulsion fans and nozzles in a distributed propulsion arrangement.

Generating a nozzle design that successfully met all these requirements proved to be quite the challenge.

Table 1: Exit dimensions of high aspect ratio nozzles.

\begin{tabular}{ccccc} 
Aspect Ratio & Height [in] & Width [in] & Area $\left(A_{j e t}\right)\left[\mathrm{in}^{2}\right]$ & $\begin{array}{c}\text { Equivalent } \\
\text { Diameter } \\
\left(D_{e q}\right)[\mathrm{in}]\end{array}$ \\
\hline $8: 1$ & 2.227 & 17.820 & 39.685 & 7.108 \\
$12: 1$ & 1.818 & 21.822 & 39.672 & 7.107 \\
$16: 1$ & 1.575 & 25.197 & 39.685 & 7.108
\end{tabular}




\section{Numerical Screening Simulations of Nozzle Designs}

\section{A. Wind-US Flow Solver}

Screening simulations of each nozzle design were performed using Wind-US v $4^{4,5}$. Wind-US is a general-purpose, Reynolds-Averaged Navier-Stokes (RANS) Computational Fluid Dynamics (CFD) solver for both structured and unstructured grids. The code is developed and managed by the NPARC Alliance, a partnership between NASA Glenn Research Center, USAF Arnold Engineering Development Complex, and The Boeing Company. Wind-US offers several numerical schemes, as well as several zero-, one-, and two-equation turbulence models. A second-order Roe numerical scheme was used for all structured simulations. The Menter Shear Stress Transport (SST) turbulence model ${ }^{6}$ was used for the screening simulations.

\section{B. Nozzle Flow Conditions}

For all simulations, the jet exhausted into a quiescent freestream, with a static temperature of $530^{\circ} \mathrm{R}$ and static pressure of $14.3 \mathrm{psi}$. The freestream Mach number was 0.01 . It has been found that compressible flow solvers, including Wind-US, struggle with convergence for nozzle flows when the freestream velocity is set to zero; even a small freestream velocity helps the solver converge the solution more quickly. At the nozzle inflow, the total temperature was set to $530^{\circ} \mathrm{R}$; the total pressure was set to 26.612 psi, corresponding to a nozzle pressure ratio (NPR) of 1.861 and a jet Mach number, $M_{j e t}$, of 0.98 . The resulting ideally expanded jet velocity, $U_{j e t}$, was $1017 \mathrm{ft} / \mathrm{s}$.

\section{Grids}

Structured grids for each nozzle design were created with the commercial code Pointwise ${ }^{7}$. The grids made use of symmetry such that a grid was constructed for only half of each nozzle. The symmetry plane was located along the height (or short) axis of the round-to-rectangular high aspect ratio (HAR) nozzle. Typically, "C" grids are used to fill the domain of half-cylindrical geometries; " $\mathrm{H}$ " grids are used to fill the domain of rectangular geometries. The round-to-rectangular nozzles created a bit of a challenge, as the upstream portion of the nozzle geometries were cylindrical and suited for " $\mathrm{C}$ " grids. Yet, the downstream portion of the nozzle geometries were rectangular and better suited for " $\mathrm{H}$ " grids. Using only one of either method to fill the flow domain of the entire nozzle would create a range of unfavorable grid cells: highly-skewed cells; cells that didn't resolve the geometry adequately; and singularities. A two-step grid was created, utilizing a "C" grid structure near the internal surface of the nozzle and an " $\mathrm{H}$ " grid in the center of the nozzle. An example of this grid topology is illustrated in Figure 2. The grid topology of the external flow simply extended the " $\mathrm{C}$ " grid outward. Viscous grid spacing was used, with a wall spacing of 0.0002 inches. Based on the skin friction at the throat, the grid spacing gave an average $y^{+}$value of two at the wall. The grid extended downstream 280 inches $\left(25.3 \times D_{\text {eq }}\right)$, and radially outward a minimum of 55 inches $\left(7.7 \times D_{\text {eq }}\right)$. The nozzle inflow extended 30 inches $\left(4.2 \times D_{\text {eq }}\right)$ upstream. The grids ranged in size from 9.2 million cells (early HAR nozzle designs) to 33.5 million cells (later HAR nozzle designs). A grid convergence study was performed; it will be discussed in the Results section (Section IV.B).

\section{Convergence}

In general, the simulations were run with global CFL number to obtain a steady state solution. Grid sequencing was used to speed up the convergence of the simulations. The convergence of each simulation was tracked in multiple ways. The mass flow and thrust at the nozzle exit were monitored. While nozzle mass flow and thrust were not of primary interest to this study, these quantities quickly indicated if the jet flow was converging steadily or if the solution had some level of unsteady behavior. Once the nozzle massflow and thrust had converged, the flowfields inside the nozzle and in the jet plume were observed over a few thousand cycles to verify that the solution had reached a state of convergence. For one or two simulations, the flowfield of the solution appeared asymmetric inside the nozzle. This 
asymmetry was unexpected as all the nozzles were designed to be symmetric about the $x-y$ plane and the $x-z$ plane. An asymmetric solution could indicate some unsteady behavior in the simulation. For these cases the simulations were run time-accurately (i.e., with a global time-step) in order to see if the solutions truly exhibited unsteady behaviors. In the cases that did exhibit asymmetry within their flowfields, continuing the simulation using a global time-step helped the solution converge without asymmetries. All simulations were completed on the multi-node, multi-core NASA Advanced Supercomputing (NAS) Pleiades supercomputer ${ }^{8}$. Each simulation used between 32 and 100 processor cores each (depending upon the grid size) and took about a week to complete.

\section{Nozzle Designs}

Round-to-rectangular high aspect ratio (HAR) nozzles were designed for three nozzle aspect ratios: 16:1, 12:1, and 8:1. Early in the design process, it was decided that the nozzle with the exit area aspect ratio of 16:1 would likely be the most challenging to design, as the final span of the nozzle would be the largest and would require the greatest amount of flow turning. Therefore, efforts were concentrated on designing a good HAR nozzle with an exit area aspect ratio of 16:1. It was assumed that using similar design methods would yield good nozzle designs with exit area aspect ratios of 12:1 and 8:1. In the spirit of brevity, only the more significant HAR nozzle designs will be highlighted in the following discussion - it will be noticed that several design iterations will be omitted.

\section{A. Initial Designs with SUPIN}

Early in the design process, it was suggested that the SUPIN code could be used to help design these nozzles, because round-to-rectangular HAR nozzles looked very similar to some supersonics inlets - just backwards. SUPIN is a computation tool that can be used to design and analyze externalcompression supersonic inlets9. SUPIN can be used to design a number of different inlet geometries, including axisymmetric outward-turning, two-dimensional single-duct, two-dimensional bifurcatedduct, and streamline-traced Busemann inlets. Slater (the developer) provided a modified version of SUPIN to use for round-to-rectangular HAR nozzle design. Upon reviewing the various inputs parameters for SUPIN, the important parameters were categorized according to Table 2. The "fixed parameters" include parameters fixed by the HAR nozzle requirements; the "variable parameters" include parameters that could be varied to generate new HAR nozzle designs.

Table 2: Input parameters required by modified version of SUPIN.

Fixed Parameters Variable Parameters

Inflow Radius

Exit Area

Aspect Ratio

\author{
Nozzle Contraction Length \\ Length of Constant Area Exit \\ Superellipse Parameter \\ y-Position of Exit \\ NURBS CURVE Parameters (4)
}

Several HAR nozzle designs were generated using SUPIN. The second design was selected to have a screening simulation performed using Wind-US. This design became known as the "A16.2" design, in which "A16" represents a nozzle aspect ratio of 16:1 and the "2" represents the second set of design parameters. This naming convention was used for all subsequent HAR nozzles. The SUPIN input parameters for the A16.2 nozzle are presented in Table 3. Based on the Nozzle Contraction Length and the Length of Constant Area Exit parameters, the total length of the A16.2 HAR nozzle design was 24.26 in. Figure 3 shows a three-view and isometric view of the A16.2 nozzle design. 
Table 3: SUPIN input parameters for the A16.2 nozzle design.

Parameter

Inflow Radius

Exit Area

Aspect Ratio [1/AR]

Nozzle Contraction Length

Length of Constant Area Exit

Superellipse Order

$\mathrm{y}$-Position of Exit

NURBS CURVE Parameters (4)
Value

5.1450 in

39.68 in $^{2}$

0.06250

23.0628 in

$1.2 \mathrm{in}$

10.0

$0.0 \mathrm{in}$

$0.9500,0.4000,0.2000,-0.2000$

A structured grid was generated for the A16.2 HAR nozzle design and a screening simulation was performed using the Wind-US Reynolds-Averaged Navier-Stokes (RANS) flow solver. Streamwise velocity contours are shown along the symmetry planes in Figure 4 . While the flow along the $x-z$ plane is interesting to look at, there is not much of interest in the $x-y$ plane. The $x-y$ plane will be left out in similar plots for subsequent nozzle designs. It was quickly realized that some unfavorable flow features are present. Looking at Figure $4 \mathrm{~b}$, it is observed that the boundary layer along the diverging (or, outboard) wall of the nozzle (from $x / D_{e q}=-2.4$ to $x / D_{e q}=-1$ ) grows substantially, though the flow does not separate. A second deficiency is that a weak normal shockwave is present at the exit plane along the centerline. It is believed that an aerodynamic throat forms in the constant area region near the exit, causing the flow to accelerate beyond Mach 1 and then undergo a weak shock to properly expand to the external pressure. Figures 5 and 6 show contours of streamwise velocity and total pressure, respectively, at the nozzle exit plane. The influence of the thick boundary layer and separated flow is quite apparent: there are losses in both velocity and total pressure along the outboard walls of the nozzle in the vicinity of the exit. Figure 7 shows contour plots of vorticity at several x-stations through the A16.2 nozzle. A pair of vortices forms along the outboard wall as the flow is pushed outward (in the $z$-direction). The vortices persist to the nozzle exit. A closer inspection of the vortices at the nozzle exit plane, pictured in Figure 8, shows that the flow is pushed outward along the upper and lower walls of the nozzle, before being redirected inward along the horizontal symmetry plane (the $x-z$ plane). The presence of the various non-uniformities that could produce noise (substantial boundary layer growth, velocity and total pressure losses, and vortices) was deemed too risky, so the A16.2 nozzle design was deemed unacceptable.

Attempts were made to improve upon the A16.2 design using SUPIN. However, even after altering various parameters and running RANS simulations, the generated nozzle designs all looked too similar and seemed to include what were thought to be negative features. Recalling Figure 3, the A16.2 HAR nozzle design was not smooth in its transition from round to superellipse near the nozzle inflow. Furthermore, it also did not seem possible to control the spanwise divergence or the area contraction using SUPIN. Therefore, it was concluded that SUPIN was really only an inlet design and analysis tool, not a nozzle design tool. It was time to create a new tool to generate HAR nozzle designs with greater control over the shape of the nozzle.

\section{B. Grid Convergence Analysis}

Before progressing further into the development of the HAR nozzle designs, it is good to pause and determine if the solution was grid independent, i.e. grid converged. This is accomplished by comparing the RANS solutions of multiple grids of differing resolutions. The A16.2 HAR nozzle design was used to study grid convergence. Since the grid was structured, the grid convergence study was easily accomplished by comparing solutions for RANS simulations that used every grid point (the "fine" grid) and every other grid point in each direction (the "coarse" grid). The A16.2 nozzle fine grid consisted of 9.3 million grid cells. The A16.2 nozzle coarse grid used one eighth the number of cells as the fine grid, giving it a size of 1.15 million cells. Although not of primary interest to the HAR nozzle design, the discharge coefficient, $C_{d}$, and thrust coefficient, $C_{v}$, were computed and compared for the coarse and fine grid solutions. The discharge coefficient, $C_{d}$, and thrust coefficient, $C_{V}$, were computed as: 


$$
\begin{gathered}
C_{d}=\frac{\int_{A_{j e t}}(\rho \cdot u) \cdot d A}{\rho_{j e t} \cdot U_{j e t} \cdot A_{j e t}} \\
C_{V}=\frac{\int_{A_{j e t}}\left[\rho \cdot u^{2} \cdot\left(p-p_{\infty}\right)\right] \cdot d A}{U_{j e t} \cdot \int_{A_{j e t}}(\rho \cdot u) \cdot d A}
\end{gathered}
$$

For the coarse grid, $C_{d}=0.9833$ and $C_{V}=0.8835$; for the fine grid, $C_{d}=0.9810$ and $C_{V}=0.8840$. Therefore, the difference between the two grid solutions was $0.2 \%$ for $C_{d}$ and $0.06 \%$ for $C_{V}$. Based on discharge and thrust coefficients, the A16.2 nozzle solution appears to be grid independent. But, the flowfield is of greater concern for this HAR nozzle design study. In Figure 9, contours of streamwise velocity along the $x-z$ symmetry plane are compared for the coarse and fine grid solutions. There is good agreement between the two solutions. The only real difference is that the boundary layers along the outboard walls of the A16.2 nozzle are thinner for the coarse solution. In Figures 10 thru 12, contours of streamwise velocity, total pressure, and cross stream velocity at the nozzle exit plane are compared for the coarse and fine grid solutions. In general, the two solutions show good agreement for the overall flowfield structure. The solutions only differ along the outboard walls of the A16.2 nozzle: the magnitude of the distortion in these areas is slightly reduced for the coarse grid, as compared to the fine grid solution. This follows the thinner boundary layers observed along the outboard walls of the coarse grid solution in Figure 9. While there are some small differences between the coarse and fine grid solutions, it concluded that the fine grid solution should be very close to grid independent, although a finer grid (with eight times more cells) was not examined. Therefore, it is assumed that using similar practices to construct grids for subsequent HAR nozzle designs will yield grid independent solutions.

\section{Segmented Nozzle Designs}

The next idea for generating HAR nozzle designs was to design the nozzle in several segments, each segment would focus on varying one or two aspects of the design, such as superellipse order, area contraction, or spanwise growth. A new Fortran code was written to generate these segmented nozzles. The A16.6 HAR nozzle design consisted of four segments:

1. Transition from circular to order 10 superellipse; grow major axis (span) to nozzle exit width via cubic polynomial; maximum divergence angle less than $33^{\circ}$; constant area.

2. Transition from order 10 superellipse to order 100 via exponential function; constant area.

3. Contract area to nozzle exit area ( $100 \%$ of total contraction) using cubic polynomial for minor axis (height).

4. Constant area and shape to nozzle exit.

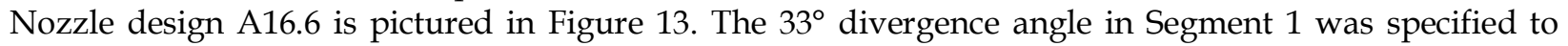
generate a nozzle about 24 inches long - the actual length was 24.22 inches. The final superellipse order of 100 was chosen to produce a nearly rectangular nozzle exit. One of the most significant design choices of the A16.6 nozzle design was that all the area contraction is in Segment 3, after the span grows and just upstream of the exit. It was thought that having the area contraction so far downstream would help suppress the boundary layer that had grown through the spanwise expansion in Segment 1. As with the A16.2 nozzle design, a RANS screening simulation was performed for the A16.6 nozzle design. Figure 14 shows contours of streamwise velocity along the symmetry planes for the A16.6 nozzle. Like the A16.2 nozzle design, the boundary layer grows along the outboard wall as the span expands from $x / D_{e q}=-2.6$ to $x / D_{e q}=-0.8$. The flow does separate at $x / D_{e q}=-1.8$, but it reattaches by $x / D_{e q}=-1.7$. Additionally, a weak normal shock is present at the exit plane along the centerline. And, as observed in Figure 15, a pair of vortices is present along the outboard wall.

\section{Investigating the Addition of Turning Vanes}

Turning vanes were added to the A16.6 nozzle design in an attempt to distribute the flow to the outboard walls. The vanes were placed along curves that divided the internal cross section area into six equal areas. This is shown in Figure 16. The vanes were modeled by applying an inviscid wall boundary condition to grid zonal interfaces located along the vane curves. Two simplifications were made to the 
simulation by modeling the vanes in this manner. First, by modeling the vanes as infinitely thin, rather than a finite thickness, a single grid could be constructed for simulations with and without vanes. Furthermore, the length and position of the vane could easily be modified by applying the wall boundary condition where necessary. Second, by modeling the vanes as inviscid surfaces, rather than viscous, it was possible to use a coarser wall grid spacing along the turning vanes, with a wall spacing of 0.01 inches, rather than 0.0002 inches. This reduced the size of the grid required to model the vanes and subsequently reduced the computational expense to obtain a converged solution. It was assumed that the simplified vanes, modeled as inviscid and infinitely thin, would be adequate for the purposes of a screening simulation: while some of the finer details may not be captured, the simulation would show whether the vanes helped distribute the flow outwards and prevent the boundary layer from growing too much as the nozzle span increased. For the A16.6-vaneA configuration, the vanes extended from 22 inches upstream of the nozzle exit to 10 inches upstream of the nozzle exit. Figure 17 shows contours of velocity for the A16.6-vaneA design. Comparing the solution to that of the A16.6 nozzle without vanes in Figure 14, it is observed that with the turning vanes present, the flow remains fully attached to the outboard wall as the nozzle span grows, $x / D_{e q}=-2.5$ to $x / D_{e q}=-1.5$. However, the boundary layer along the outboard wall is still substantial. A shockwave of similar strength to that observed in the A16.6 nozzle without vanes still exists near the exit. Disturbances formed downstream of the turning vanes. This flow feature would typically be attributed as the vanes' wakes, however that is not the case here since the vanes were modeled with an inviscid wall boundary condition. Figure 18 shows the presence of vorticity in these disturbances at the nozzle exit plane, indicating that the disturbances are causes by rotational flow shedding from the turning vanes. The disturbances would likely be amplified and become actual wakes if the vanes were modeled with a viscous wall boundary condition. The additional non-uniformity in the flow at the nozzle exit will likely interfere with the septa inserts when they are added for the experimental acoustics measurements.

\section{E. Further Segmented Nozzle Designs}

The subsequent nozzle design - A16.7 - continued using the segmented approach, but modified the parameters of each segment. The A16.7 nozzle design composed of the following segments:

1. Transition from circular to order 10 superellipse; grow major axis (span) to nozzle exit width using cubic polynomial; maximum divergence angle less than $28^{\circ}$; linear area contraction, $91.3 \%$ of total contraction.

2. Transition from order 10 superellipse to order 100 via exponential function; linear area contraction, $8.3 \%$ of total contraction.

3. Complete linear area contraction, $0.4 \%$ of total contraction.

4. Constant area and shape to nozzle exit.

The A16.7 HAR nozzle design is pictured in Figure 19. The major difference between the A16.6 nozzle design and the A16.7 nozzle design was that the latter includes area contraction through Segments 1 through 3, rather than only in Segment 3. Like all previous nozzle designs, the A16.7 design held the area and shape constant for the final 1.0 inch upstream of the nozzle exit. The RANS screening simulation for the A16.7 nozzle design showed that the boundary layer along the outboard surfaces did not grow nearly as much as for previous designs. This is observed in the velocity contours presented in Figure 20. However, the normal shockwave at the nozzle exit appeared to be stronger than that of the A16.6 nozzle design (refer to Figure 14). Contours of vorticity are plotted at the exit plane of the A16.7 nozzle in Figure 21. Comparing these to vorticity flowfield of the A16.6 nozzle (Figure 15), it is observed that the pair or vortices along the outboard wall are smaller in size for the A16.7 nozzle than the A16.6 nozzle. However, the shockwave at the exit plane of the A16.7 nozzle generates more vorticity than is observed for the A16.6 nozzle. While the A16.7 design's thinner boundary layer along the outboard surfaces was favorable, the normal shock at the exit plane was still not acceptable.

\section{F. Final Segmented Nozzle Design}

What eventually became the final nozzle design sought to incorporate what were believed to be the most beneficial features of the previous nozzle designs: smooth transition from round to rectangular 
cross section shape and area contraction through each segment. At this time, it also became apparent that the septa inserts would require greater nozzle length - a minimum of 5.5 inches. However, it was also determined that the region occupied by the septa inserts could also include some area contraction, but only in the height of the nozzle exit - the span of the nozzle had to remain constant to reduce complexity. Taking into consideration these adjusted requirements, the A16.10 nozzle design was developed, composed of three segments:

1. Transition from circular to order 10 superellipse; grow major axis to nozzle exit width via cubic polynomial; maximum divergence angle less than $33^{\circ}$; linear area contraction, $75.7 \%$ of total contraction.

2. Transition from order 10 superellipse to order 100 via exponential function; linear area contraction, $4.3 \%$ of total contraction; constant major axis (span) length.

3. Linear area contraction, $20 \%$ of total contraction; constant major axis (span) length and constant superellipse order; longer segment length (5.5 inches) to accommodate septa inserts.

The A16.10 nozzle design is shown in Figure 22. The length of the A16.10 HAR nozzle design was specified to be 24 inches. As with the previous HAR nozzle designs, a RANS screening simulation was performed for the A16.10 nozzle. The streamwise velocity contours are shown in Figure 23. The boundary layer along the outboard surface grows fairly thick as the nozzle span increases - more so than for the A16.7 nozzle (Figure 20) - however, the flow remains attached through the entire length of the nozzle. Furthermore, unlike the A16.7 nozzle, the A16.10 nozzle shows no evidence of a normal shockwave forming along the centerline at the nozzle exit. Figure 24 shows the contours of vorticity through the A16.10 nozzle. A pair of vortices is present along the outboard wall near the nozzle exit. The vortices have a vorticity magnitude that is about $15 \%$ greater $\left(W \times\left(D_{e q} / U_{j e t}\right)=42.6 \mathrm{vs.} W \times\left(D_{e q} / U_{j e t}\right)=36.8\right)$ than those of the A16.7 nozzle (recall Figure 21). Figure 25 shows the magnitude of the cross-stream velocity along the nozzle exit plane of the A16.10 nozzle. The maximum velocity of the secondary flow in the vortices is about $8.5 \%$ of the jet exit velocity. The A16.10 nozzle showed the best blend of favorable (and unfavorable) flow characteristics, so far.

Screening simulations of the A16.10 nozzle were performed with turning vanes and a center vane added to the nozzle. The turning vanes stretched from 21.5 inches upstream of the nozzle exit to 6.5 inches upstream of the nozzle exit. The center vane stretched the entire 24 inch length of the nozzle. Figure 26 shows the location of the turning vanes. Like before, the vanes were modeled using wall boundary conditions at grid zonal interfaces, making the vanes infinitely thin (this was deemed a reasonable assumption, since actual turning vanes would likely be composed of a thin sheet metal). However, to increase the fidelity of the screening simulations, the vanes were modeled with viscous wall boundary conditions. This also meant that a viscous wall spacing ( 0.0002 inches) was used in the grid along the turning vanes. A center vane was added because initial mechanical analyses of earlier HAR nozzle designs indicated a center vane was required to prevent the nozzle from deforming near the exit. Therefore, two additional screening simulations were performed: the A16.10 nozzle with center vane only and the A16.10 nozzle with center vane and turning vanes. Figure 27 shows contours of velocity for along the spanwise plane for all three variants of the A16.10 nozzle. Compared to the A16.10 nozzle without vanes (Figure 27a), the A16.10 nozzle with center vane produced a wake in the nozzle plume, directly following the center vane (Figure 27b). The A16.10 nozzle with turning vanes produced five wakes, one downstream of each vane (Figure 27c). The turning vanes did direct the flow outward and reduced the amount of the boundary layer growth along the outboard walls, but only a small amount - not as much as would be hoped for. Contours of vorticity are shown at the exit plane of each A16.10 nozzle variant in Figure 28. The boundary layer from the center vane added a significant amount of vorticity to the flow along the centerline (Figure 28b). While the added vorticity from the center vane would be an unfavorable consequence of maintaining the structural integrity of the HAR nozzle, it would likely not interfere too much when the septa inserts were installed, as a septum would likely be located along the center plane and create its own wake. It is observed in Figure 28c that the turning vanes also add vorticity to the flow downstream of each vane, though not nearly of the same magnitude as added by the boundary layer from the center vane. The outboard turning vanes produced pockets of vorticity downstream of the vane and nozzle wall intersections. Closer inspection of these pockets of vorticity 
showed that they were not caused by streamwise vortices. More importantly, Figure $28 \mathrm{c}$ shows that the turning vanes did not significantly reduce the vorticity and non-uniform flow along the outboard walls of the A16.10 nozzle design, when compared to the same nozzle without turning vanes. Therefore, the decision was made to move forward with the A16.10 nozzle with center vane, as the intended benefits of turning vanes were not realized.

\section{G. Aspect Ratio 12:1 and 8:1 Nozzles}

The design approach used for the A16.10 HAR nozzle was used for two more HAR nozzles, with aspect ratios of 12:1 and 8:1. Only the aspect ratio (and shape) of the nozzle exit was changed (recall Table 1), therefore all other design parameters were maintained from the A16.10 HAR nozzle design. The A12.10 HAR nozzle design is shown in Figure 29; the A8.10 HAR nozzle design is shown in Figure 30. Like the A16.10 nozzle, the lengths of the A12.10 and A8.10 nozzles were each 24 inches. Three RANS screening simulations were performed for each nozzle design: no vanes; center vane; and center and turning vanes. The results were similar in nature to the A16.10 nozzle, discussed earlier. For brevity, only the results of the A12.10 and A8.10 nozzles with center vane will be presented. Velocity contours along the symmetry planes are shown in Figures 31 and 32. Compared to the A16.10 nozzle, the A12.10 and A8.10 nozzles suffer less growth of the boundary layer along the outboard wall. This is expected, as the flow along the outboard walls A16.10 must turn more than that of the A12.10 and A8.10 nozzles. Contours of vorticity are shown through the A12.10 and A8.10 nozzles in Figures 33 and 34. A further consequence of the reduced flow turning within the nozzle is that a pair of vortices at the nozzle exit of the A12.10 and A8.10 nozzles is lower in strength than the vortices in the A16.10 nozzle - in fact the A8.10 nozzle design has virtually no vorticity along the outboard walls, when compared to the A16.10 nozzle design. As predicted, the 16:1 aspect ratio HAR nozzle was the more challenging nozzle to design, but the design techniques easily produced nozzles with aspect ratios of 12:1 and 8:1.

\section{H. Comparison of High Aspect Ratio Nozzles}

While the purpose of the HAR nozzle designs is to mimic an array of nozzles in a distributed propulsion arrangement, it may be useful look at the designs simply as rectangular nozzles. The jet potential cores of the three HAR nozzle designs (A16.10, A12.10, and A8.3) are compared in Figure 35 for the nozzles without their center vanes. For the purposes of this report, the jet potential core is being defined as the portion of the jet plume where $u \geq 0.99 \times U_{j e t}$. As the aspect ratio of the nozzle exit increases, the jet potential core becomes shorter. This is expected: as the nozzle aspect ratio increases, the nozzle height decreases, resulting in a shorter distance of jet potential core for the shear layer to mix through. It is interesting that the shape of the jet potential cores at their downstream termination is inverted for the A16.10 nozzle, compared to the A8.10 nozzle. In other words, for the A8.10 nozzle, the jet potential core breaks down along the outboard edges first, but is sustained longer along the centerline. The opposite is true for the A16.10 nozzle: its jet potential core breaks down along the centerline first, but is sustained along the outboard edges. It is likely that the presence of the vortex pair along the outboard walls of the A16.10 nozzle distribute more energy to this part of the flow and help sustain the jet potential core longer along the outboard edges. The jet potential cores of the HAR nozzles, which end between $2.3 \times D_{\text {eq }}$ to $3.4 \times D_{e q}$, are considerably shorter than the jet potential core from a convergent round nozzle, which typically breaks down around $8.5 \times D_{e q}$ downstream of the nozzle exit for a similar nozzle pressure ratio (NPR) and RANS simulation ${ }^{10}$. However, the RANS simulations typically over-predict the jet potential core length of incompressible round jets. Experiments have shown that the jet potential core of incompressible round jets end around $5 \times D_{\text {eq }}$ downstream of the nozzle exit ${ }^{11}$. It is possible that the RANSpredicted jet potential core length from the HAR nozzle, which more closely resembles planar shear layers, may be closer to the physical jet potential core length, but experimental data will be needed to assess the performance of the RANS simulation of HAR nozzles. 


\section{Conclusions}

A series of three round-to-rectangular high aspect ratio (HAR) nozzles were designed for acoustic measurements in the NASA Glenn Research Center Nozzle Acoustic Test Rig (NATR). These nozzles had exit area aspect ratios of 8:1,12:1, and 16:1. The final nozzle designs were generated using a computer code that parameterized the nozzle in segments. The nozzles consisted of three segments:

1. Transition from circular to order 10 superellipse; grow major axis to nozzle exit width via cubic polynomial; maximum divergence angle less than $33^{\circ}$; linear area contraction, $75.7 \%$ of total contraction.

2. Transition from order 10 superellipse to order 100 via exponential function; linear area contraction, $4.3 \%$ of total contraction; constant major axis (span) length.

3. Linear area contraction, $20 \%$ of total; constant major axis (span) length and constant superellipse order; length of 5.5 inches to accommodate septa inserts.

Additionally, each HAR nozzle design included a center vane for structural integrity. Reynolds-Averaged Navier-Stokes (RANS) screening simulations showed that the flow through the HAR nozzles remained attached and free of shockwaves due to the formation of an aerodynamic throat due to boundary layer growth. While the goal was to obtain a uniform flow at the nozzle exit, all the nozzle design suffered a wake downstream of the structurally-required center vane and loss of total pressure (and streamwise velocity) along the outboard walls. Vortices developed along the outboard wall of the $16: 1$ and 12:1 aspect ratio HAR nozzles.

Through the process of developing HAR nozzles and performing screening simulations, several observations can be made regarding the design of HAR nozzles. First, it is best if the nozzle is convergent along the entire length to keep the pressure gradient favorable. In designs that included a section of constant cross-sectional area near the exit, an aerodynamic throat formed near the nozzle exit, leading to supersonic flow and a weak shock wave. Second, it may not be entirely possible to suppress vortices along the outboard walls for short round-to-rectangular nozzles with final aspect ratios of 12:1 and larger. The large amount of flow turning coupled with short length for the HAR nozzles in this study always resulted in a pair of counter-rotating vortices along the outboard walls. Only the HAR nozzle with an aspect ratio of 8:1 had weaker vortices. Next, internal turning vanes did not adequately help improve the flow at the nozzle exit of the HAR nozzles. While the turning vanes may have reduced the boundary layer growth by a small amount, they did not suppress vortices or total pressure loss along the outboard wall at the nozzle exit. Furthermore, the turning vanes added their own wake at the nozzle exit. This study showed that designing a round-to-rectangular HAR nozzle is not trivial. Much care is required to produce a nozzle that is efficient and minimizes flowfield features that could produce noise.

Lastly, this study demonstrated that RANS simulations can be extremely valuable and informative in screening designs of flow test hardware, specifically nozzles. The total turn-around time for each nozzle design ranged on the order of one to two weeks (including design generation, grid generation, and simulation time). The simulations showed the challenges and deficiencies faced by each nozzle design, before substantial amounts of money and time were spent producing hardware. The RANS screening simulations provided the opportunity for researchers to reduce risk and improve designs prior to the experimental test.

\section{Future Work}

The goal of future efforts would be to use the high aspect ratio (HAR) nozzles developed in this effort to further mimic the Hybrid-Wing-Body Distributed Propulsion concept. Septa could be added near the exit of the HAR in order to simulate the nozzles from individual engines in a distributed propulsion array. An aft deck could also be added to the lower side of the exit of the HAR nozzle to approximate the nozzles of a distributed propulsion array placed on the upper surface of a hybrid-wingbody aircraft. Both of these configurations were included in the Jet-Surface Interaction-High Aspect Ratio (JSI-HAR) tests conducted at NASA Glenn Research Center's Nozzle Acoustic Test Rig (NATR)3, however the flowfield data collected during the JSI-HAR tests was limited to static pressure measurements along the aft deck and pitot pressure measurements across the nozzle exit plane. Therefore, Reynolds-Averaged 
Navier-Stokes (RANS) simulations of the HAR nozzles with septa and/or an aft deck would provide a greater understanding of the aerodynamic performance of these configurations. The RANS simulations could provide valuable insight into the jet plume velocity and turbulent kinetic energy fields that was not observed experimentally.

\section{Acknowledgments}

This work was supported by the Advanced Air Transport Technology Project. The author is also grateful for assistance from Cliff Brown and John Slater.

\section{References}

1 NASA Research and Technology Program and Project Management Requirements, NASA Procedural Requirements (NPR) 1720.9. Appendix J. Technology Readiness Levels (TRLs), Feb. 5, 2008.

2 Kim, H., Liou, M.-F., Liou, M.-S., "Mail-Slot Nacelle Shape Design for N3-X Hybrid Wing-Body Configuration," AIAA Paper 2015-3805, July 2015.

3 Brown, Cliff, and Dippold, Vance, "Jet-Surface Interaction - High Aspect Ratio Nozzle Test Nozzle Design and Preliminary Results," Proceedings of the Acoustics Working Group Meeting, Cleveland, OH, October 20-21, 2015, GRC-E-DAA-TN27380.

4 Towne, C. E., “Wind-US Users Guide, Version 2.0," NASA/TM -2009-215804, Oct. 2009.

5 Georgiadis, N. J., Yoder, D. A., Towne, C. S., Engblom, W. A., Bhagwandin, V. A., Power, G. D., Lankford, D. W., and Nelson, C. C., "Wind-US Code Physical Modeling Improvements to Complement Hypersonic Testing and Evaluation," AIAA Paper 2009-193, Jan. 2009.

6 Menter, F. R., “Two-Equation Eddy Viscosity Turbulence Models for Engineering Applications," AIAA Journal, Vol. 32, No. 8 (1994), pp. 1598-1605. doi: 10.2514/3.12149.

7 Pointwise ${ }^{\circledR}$ [software package], Ver. 17.1 Release 4, Pointwise, Inc., Fort Worth, TX, 2013.

8 NASA High-End Computing Capability [webpage], URL: http://www.nas.nasa.gov/hecc/, [cited 1 November 2015].

9 Slater, J. W., “Design and Analysis Tool for External-Compression Supersonic Inlets," AIAA Paper 2012-0016, Jan. 2012.

10 NPARC Alliance Validation Archive: Acoustic Reference Nozzle with Mach 0.97, Unheated Jet Flow [webpage], URL: http://www.grc.nasa.gov/WWW/wind/valid/arn/index.html, [cited 1 March 2016].

11 Bridges, J. and Wernet, M., "Establishing Consensus Turbulence Statistics for Hot Subsonic Jets," AIAA Paper 2010-3751, June 2010. 


\section{Figures}

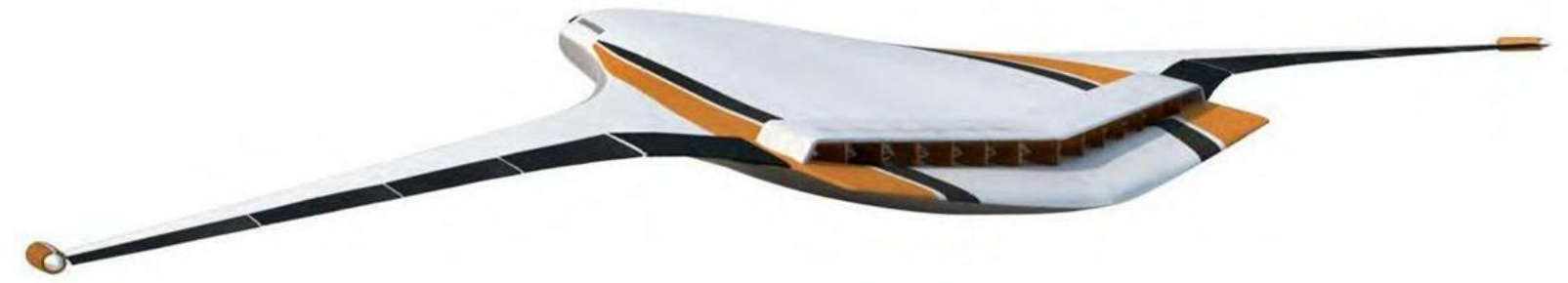

Figure 1: Illustration of Hybrid-Wing-Body aircraft concept with Turboelectric Distributed Propulsion system ${ }^{1}$. Note the use of mailslot nozzle.

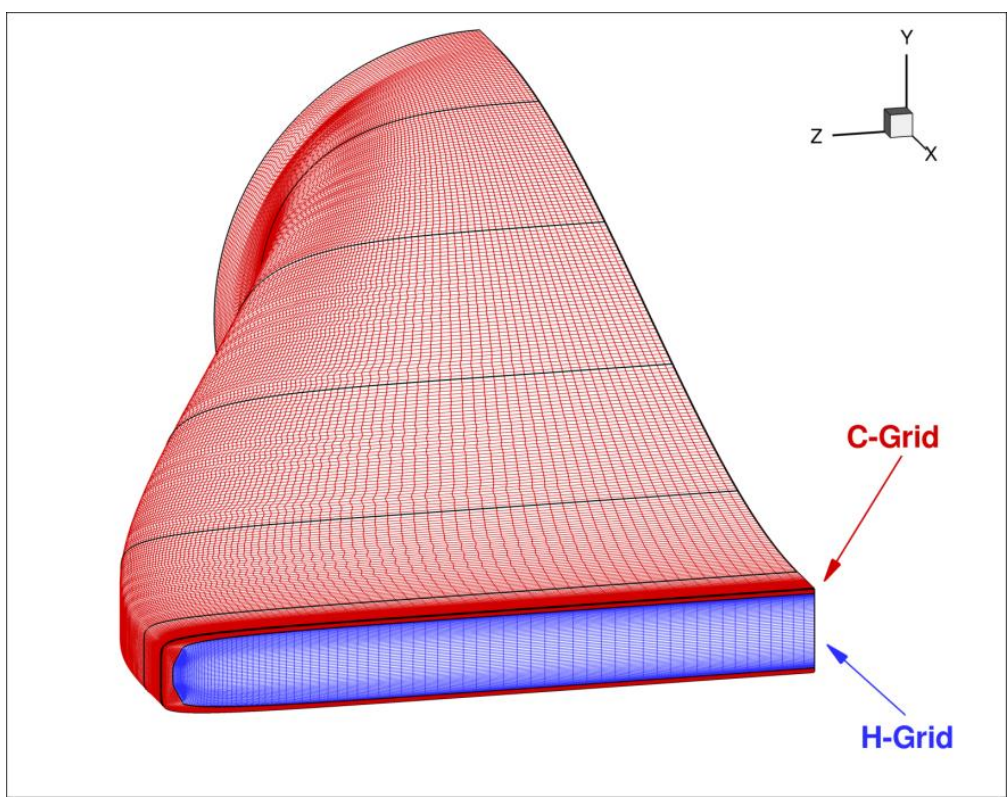

Figure 2: Example of two-step grid topology: " $\mathrm{C}$ " grid along internal surfaces of nozzle; " $\mathrm{H}$ " grid along center of nozzle.

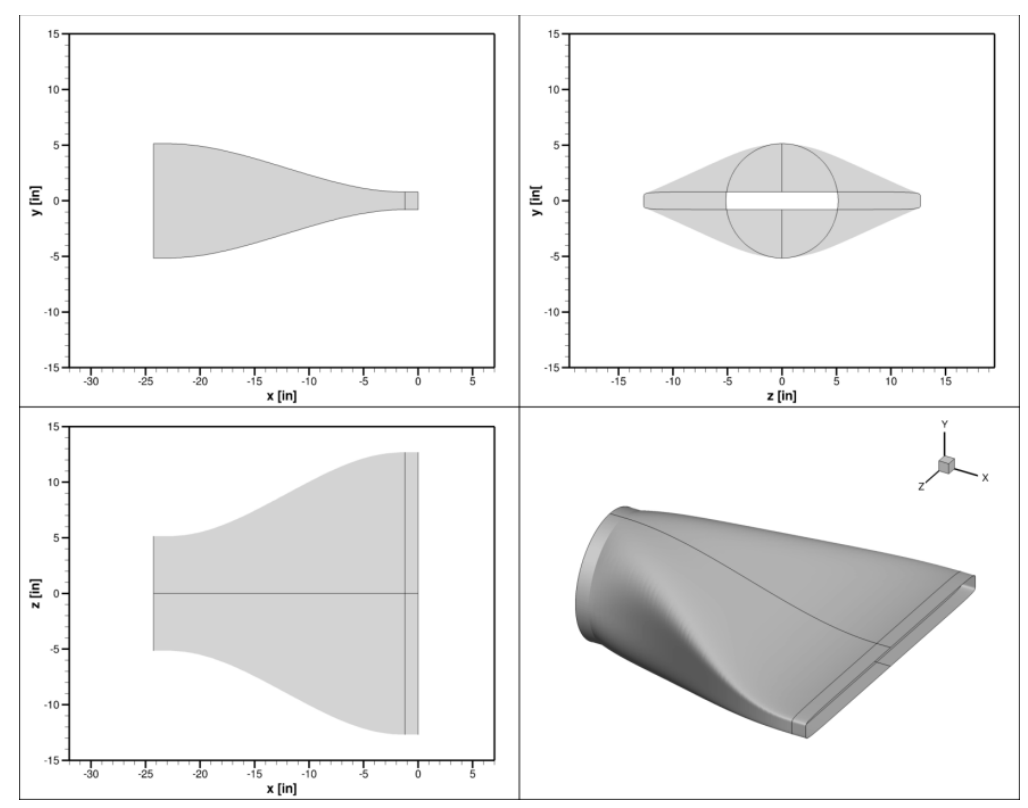

Figure 3: The A16.2 HAR nozzle design, generated using SUPIN. 


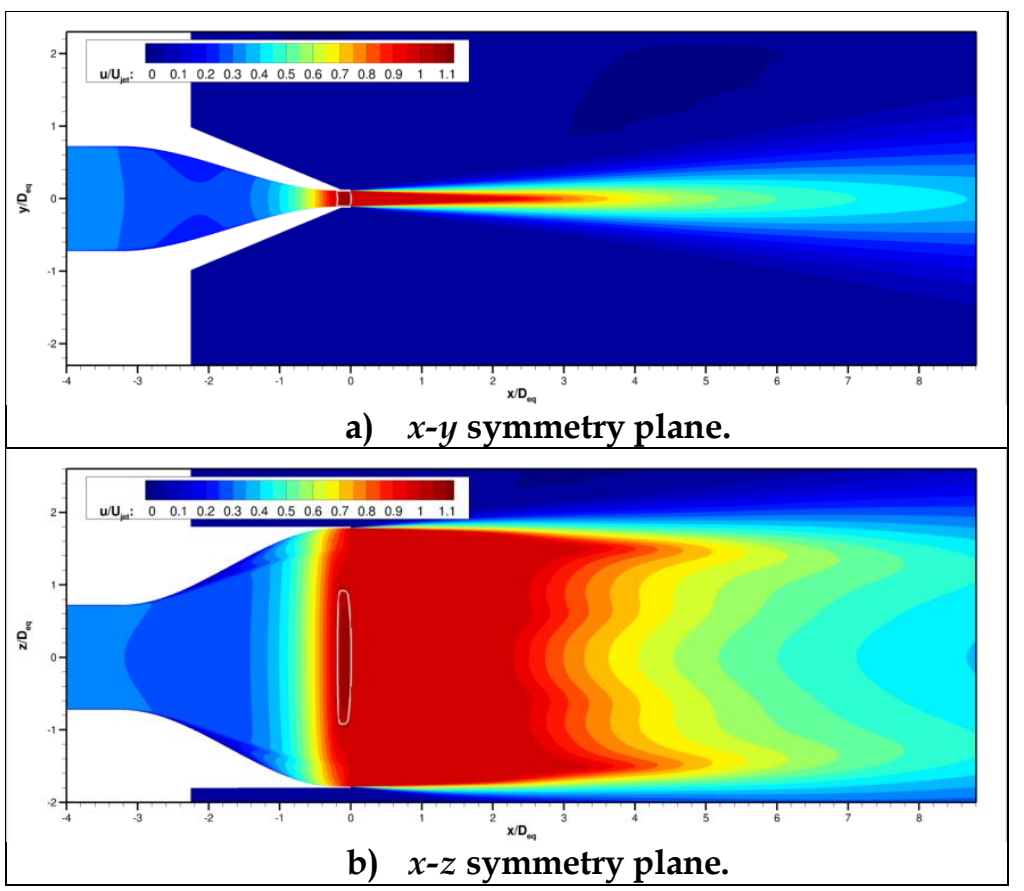

Figure 4: Contours of streamwise velocity along the $x-y$ and $x-z$ symmetry planes of the A16.2 HAR nozzle design. Light gray contour lines denote $M=1$.

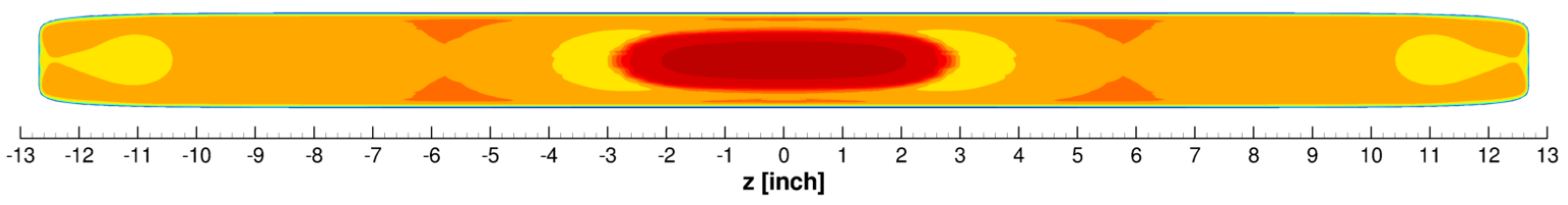

Figure 5: Contours of streamwise velocity at the exit plane of the A16.2 HAR nozzle design.

$\mathbf{p}_{0} / \mathbf{p}_{\infty}: \quad 1.81 .811 .821 .831 .841 .851 .861 .87$

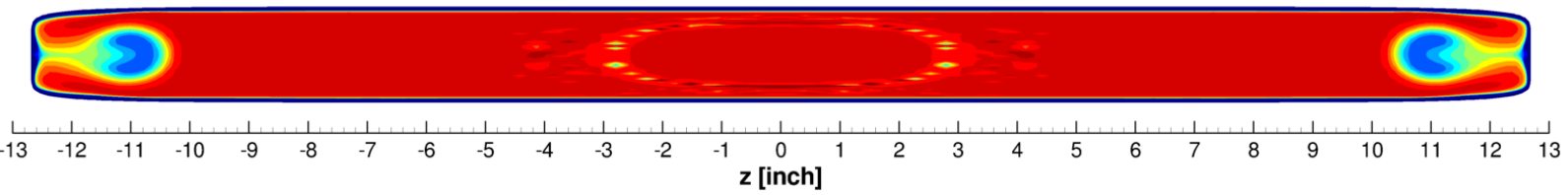

Figure 6: Contours of total pressure at the exit plane of the A16.2 HAR nozzle design. 
a) $x=-18$ inches

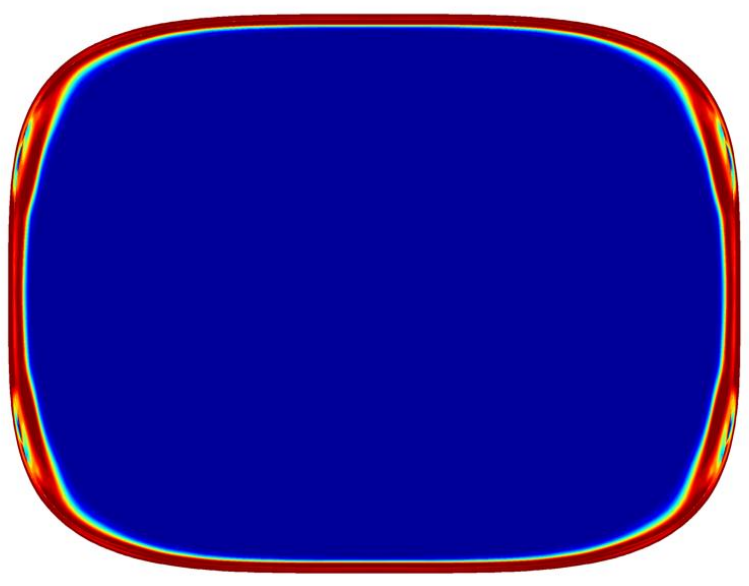

b) $x=-15$ inches

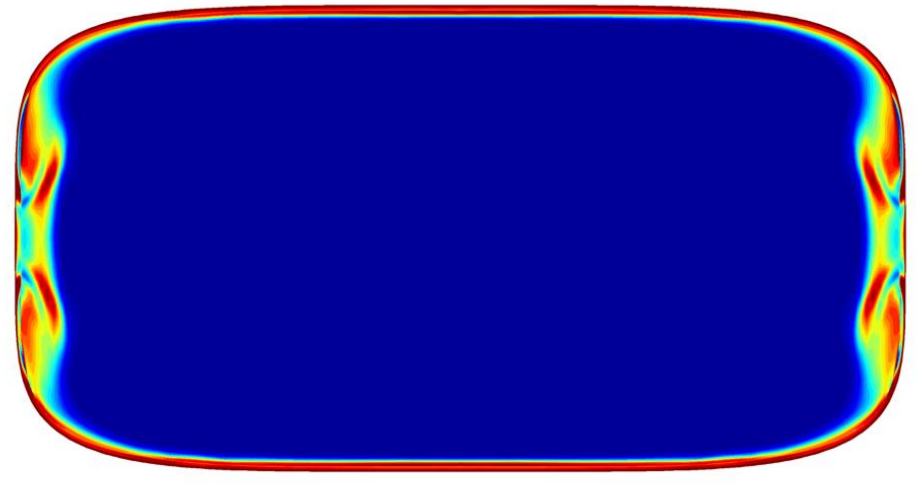

c) $x=-10$ inches

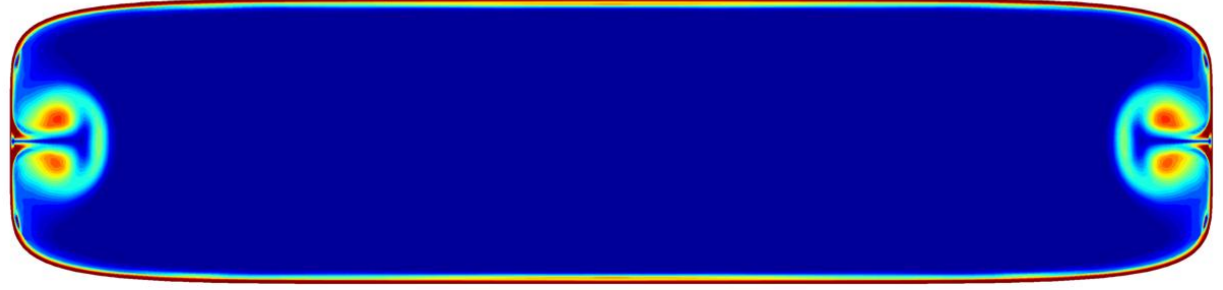

d) $x=-5$ inches

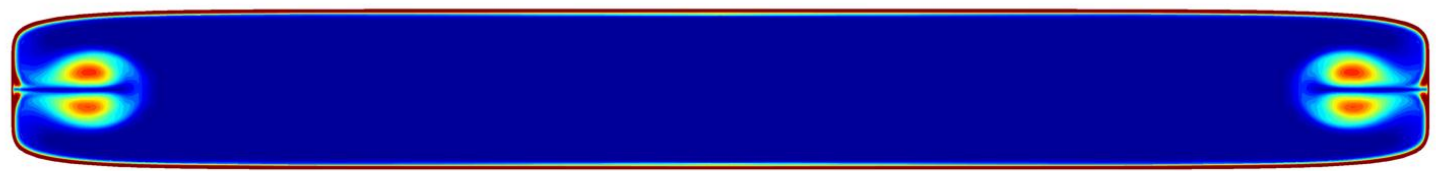

e) $x=0$ inches

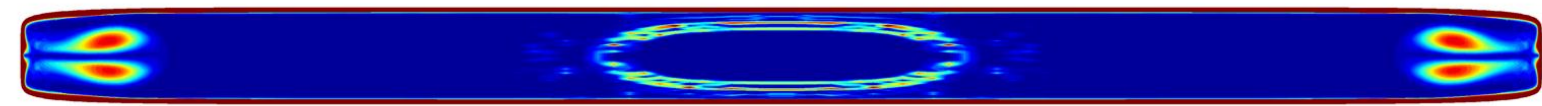

$\begin{array}{llllllllllllllllllllllllllll}-13 & -12 & -11 & -10 & -9 & -8 & -7 & -6 & -5 & -4 & -3 & -2 & -1 & \text { rinch }^{0} & 2 & 3 & 4 & 5 & 6 & 7 & 8 & 9 & 10 & 11 & 12 & 13\end{array}$

$\mathbf{W}^{\star}\left(\mathbf{D}_{\text {eq }} / \mathbf{U}_{\text {jet }}\right): 0 \quad 1020304050$

Figure 7: Contours of vorticity along x-stations inside the A16.2 HAR nozzle design. 


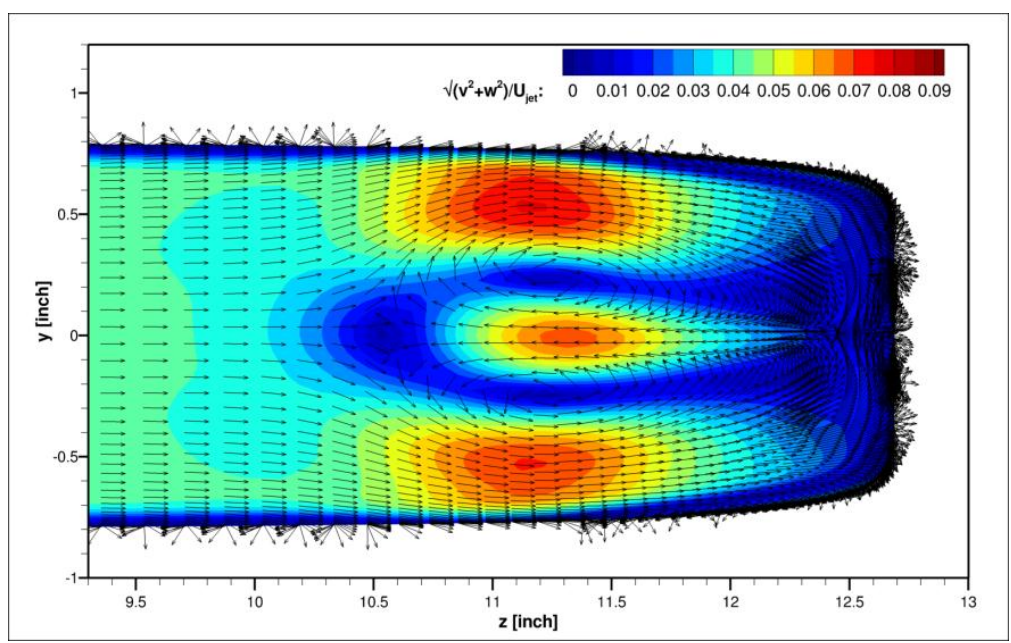

Figure 8: Plot of cross-stream velocity vectors at exit plane of the A16.2 HAR nozzle design.

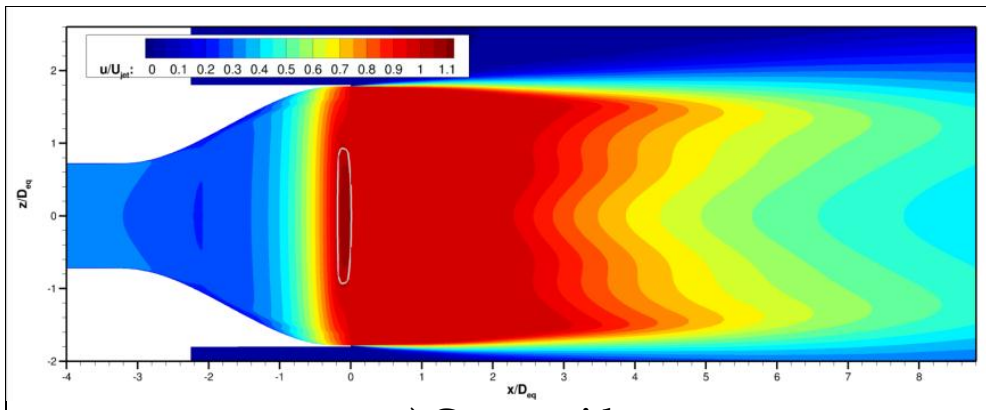

a) Coarse grid.

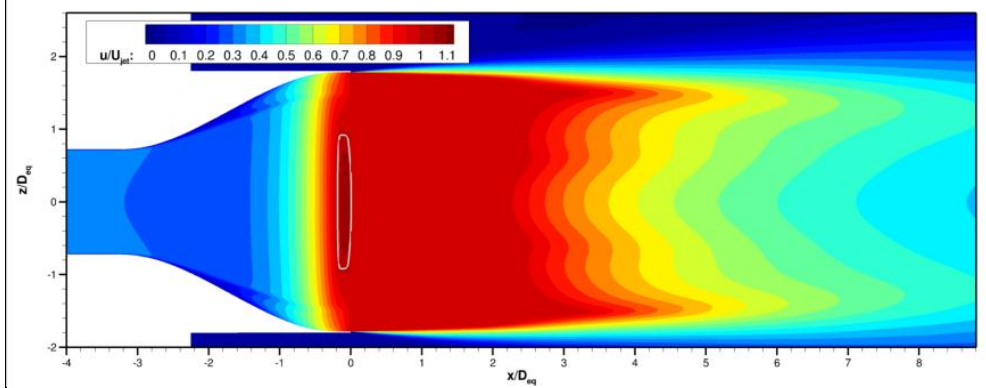

b) Fine grid.

Figure 9: Contours of streamwise velocity along the $x-z$ symmetry planes of the A16.2 HAR nozzle design. Coarse and fine grids compared. Light gray contour lines denote $M=1$. 


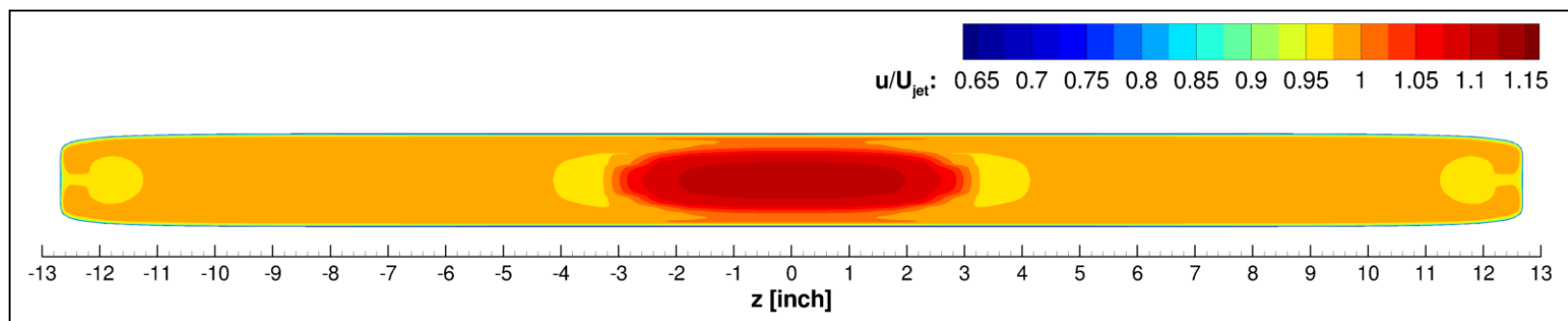

a) Coarse grid.

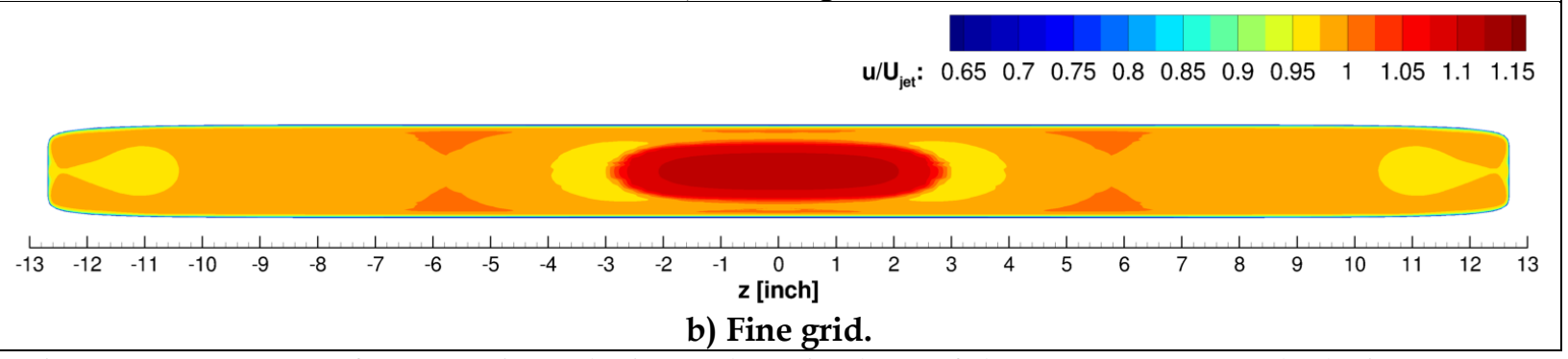

Figure 10: Contours of streamwise velocity at the exit plane of the A16.2 HAR nozzle design. Coarse and fine grids compared.

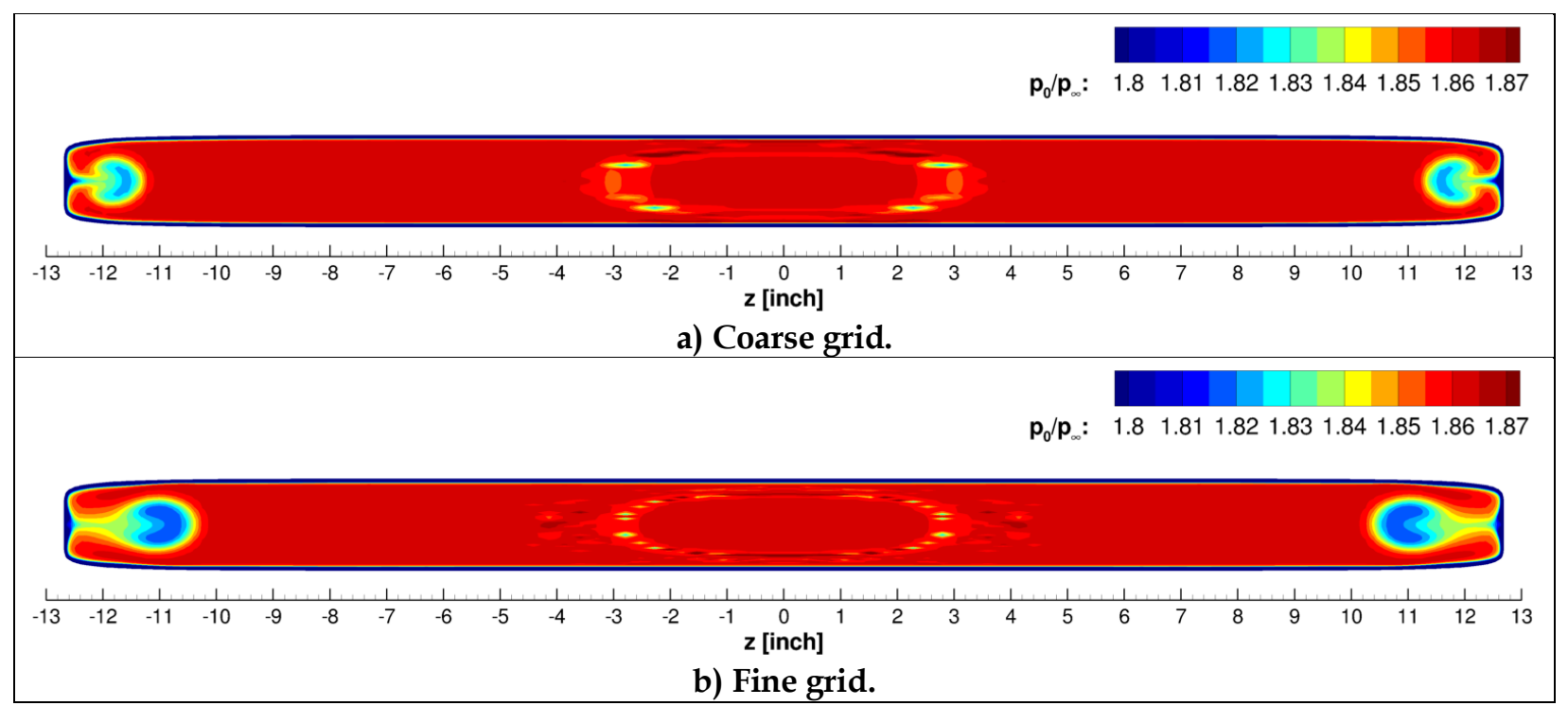

Figure 11: Contours of total pressure at the exit plane of the A16.2 HAR nozzle design. Coarse and fine grids compared. 


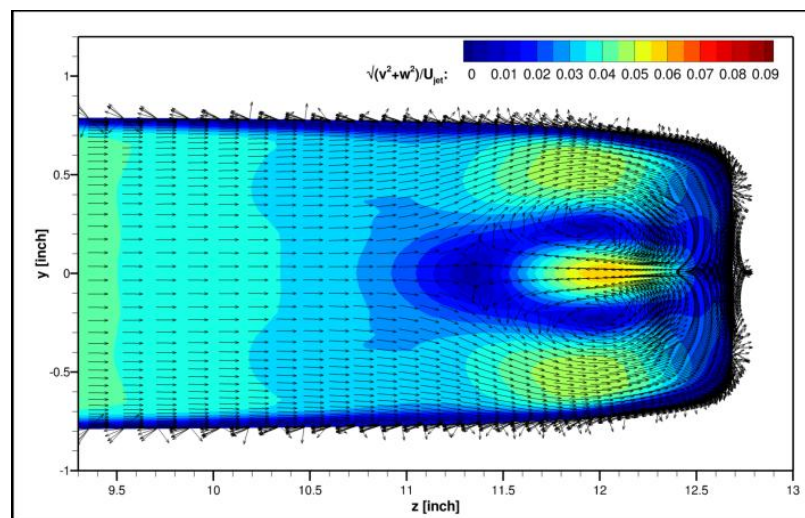

a) Coarse grid.

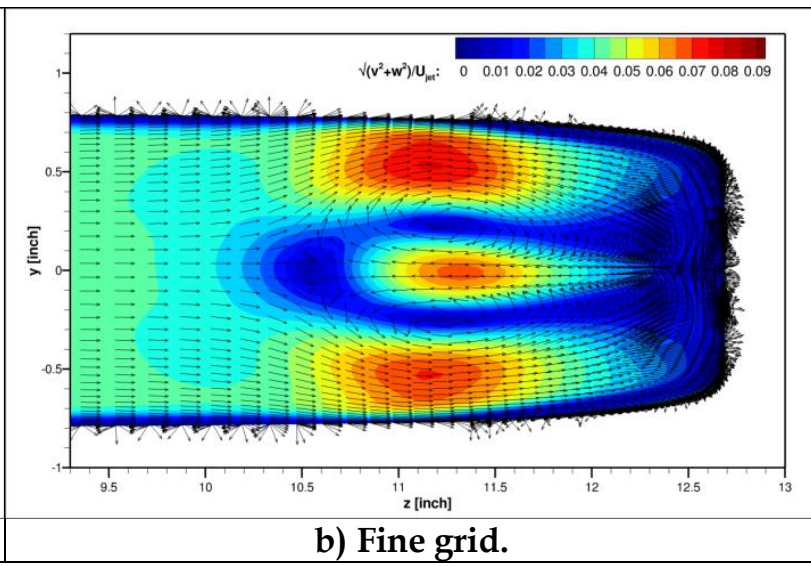

b) Fine grid.

Figure 12: Plot of cross-stream velocity vectors at exit plane of the A16.2 HAR nozzle design. Coarse and fine grids compared.

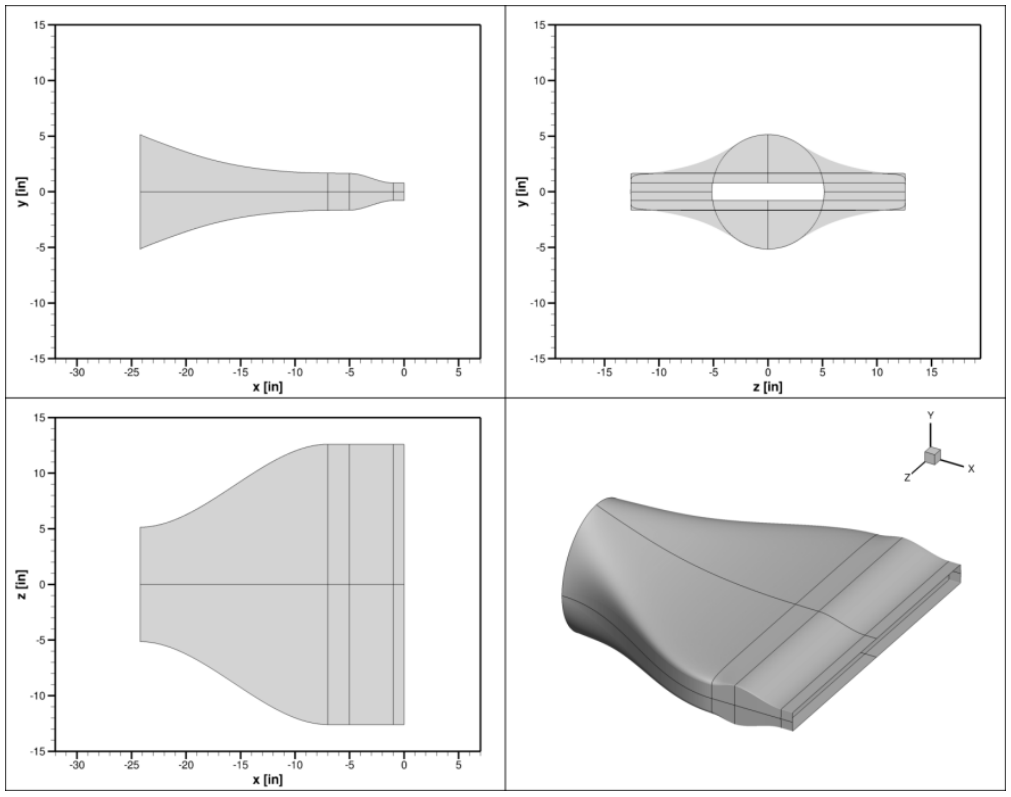

Figure 13: The A16.6 HAR nozzle design, generated using segmented approach.

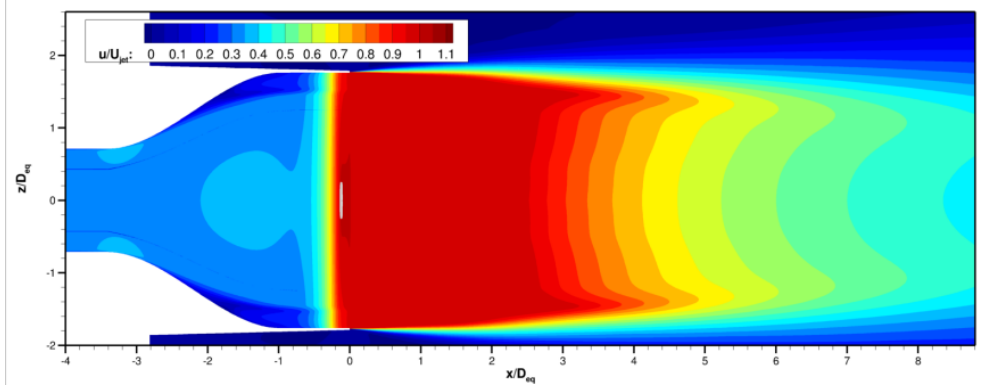

Figure 14: Contours of streamwise velocity along the $x-z$ symmetry plane of the A16.6 HAR nozzle design. Light gray contour line denotes $M=1$. 


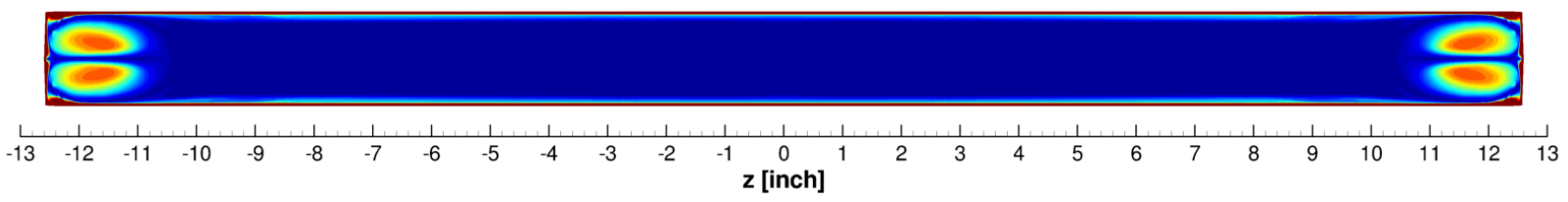

Figure 15: Contours of vorticity at the exit plane of the A16.6 HAR nozzle design.

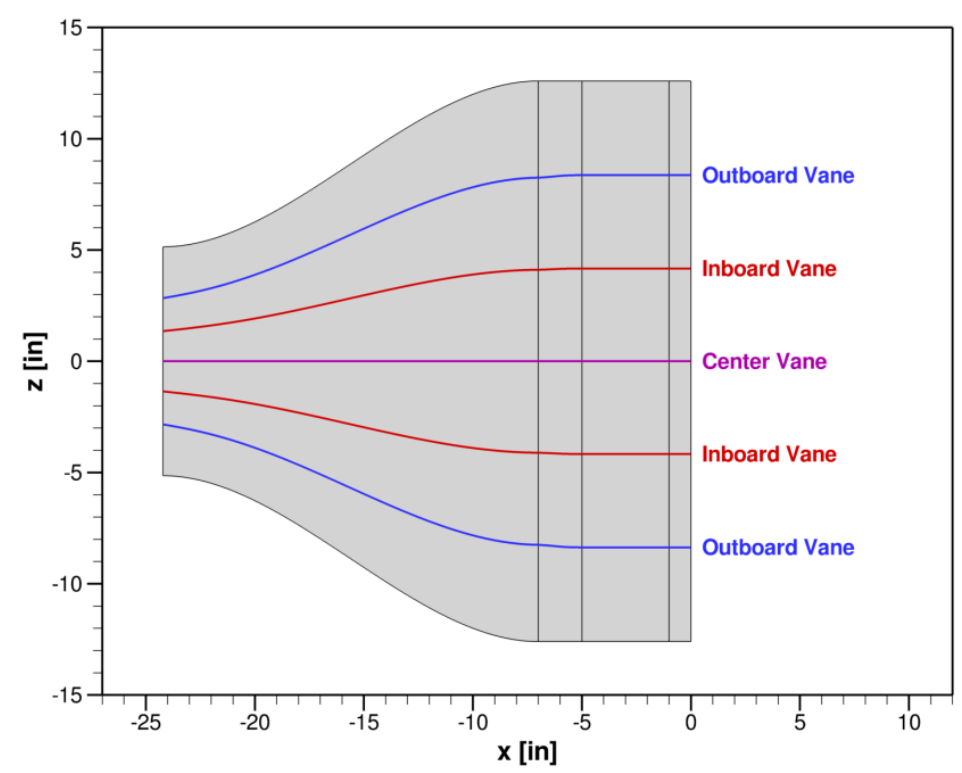

Figure 16: Curves showing locations of turning vanes for the A16.6 nozzle. The vane lines divide the nozzle's cross-sectional area into sixths.

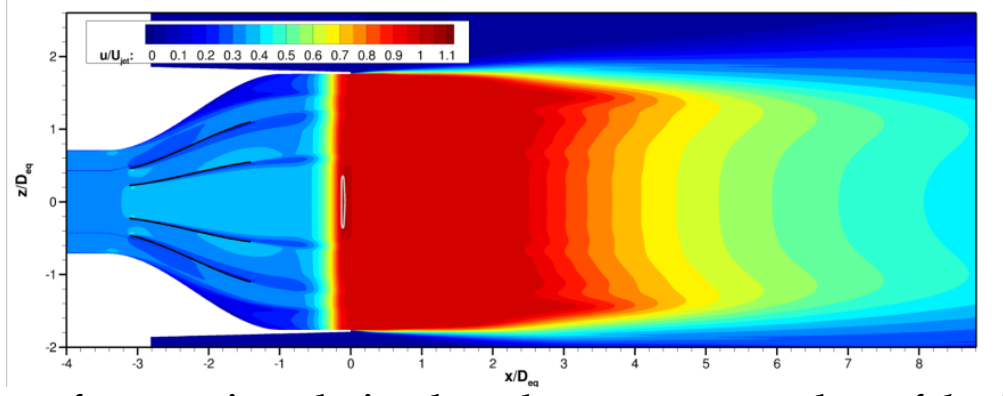

Figure 17: Contours of streamwise velocity along the $x-z$ symmetry plane of the A16.6-vaneA HAR nozzle design. Vanes are represented by black curves from $x=-22$ inches to $x=-10$ inches. Light gray contour line denotes $M=1$. 
a) $x=-20$ inches

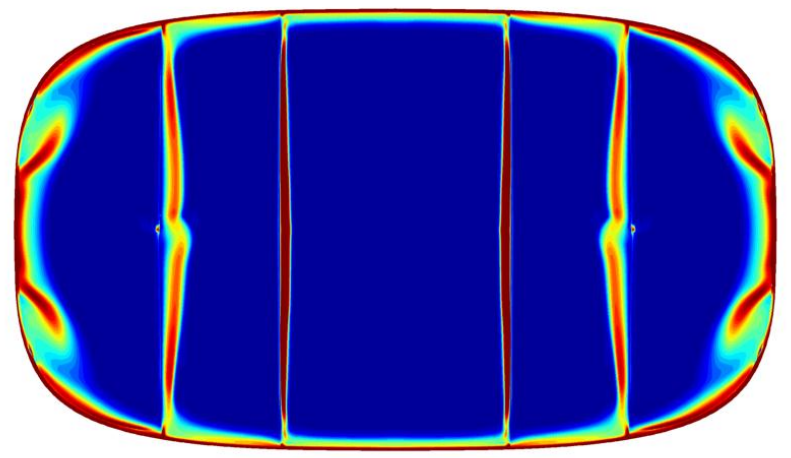

b) $x=-15$ inches

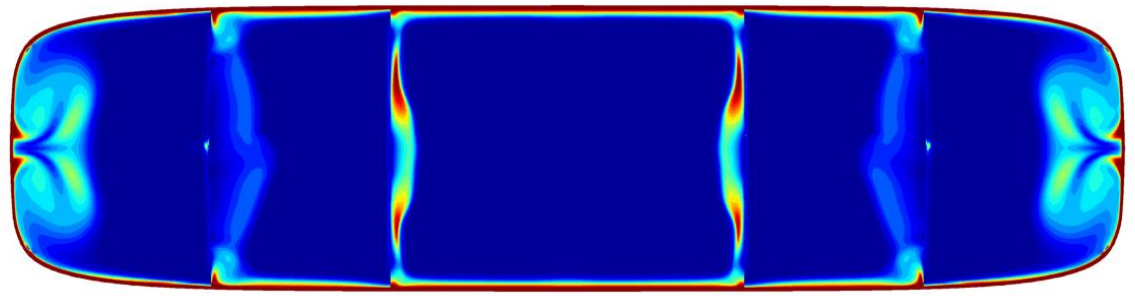

c) $x=-10$ inches

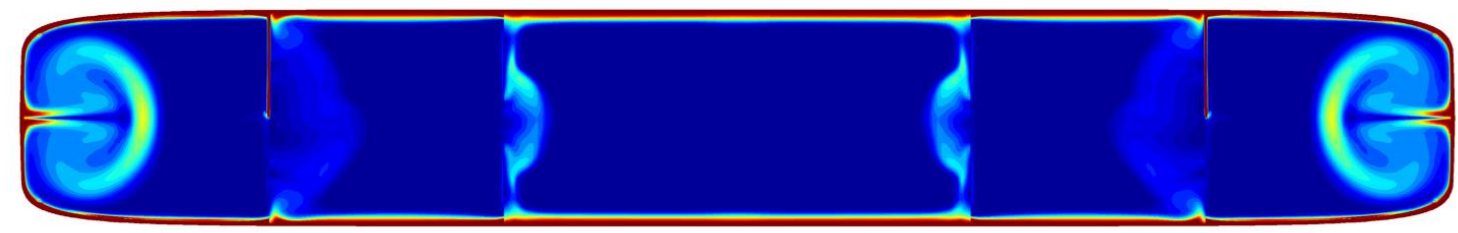

d) $x=-5$ inches

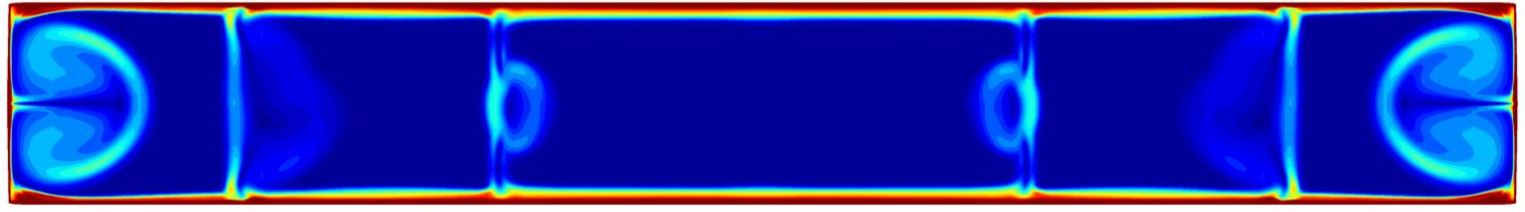

e) $x=0$ inches

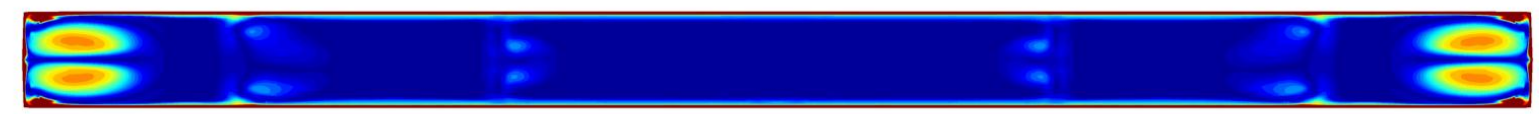

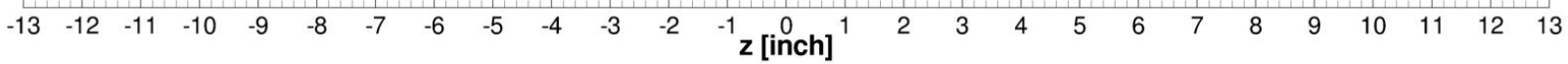

$\mathbf{W}^{*}\left(\mathbf{D}_{\text {eq }} / \mathbf{U}_{\text {jet }}\right): 0 \quad \begin{array}{lllll}0 & 20304050\end{array}$

Figure 18: Contours of vorticity along $x$-stations inside the A16.6-vaneA HAR nozzle design. 


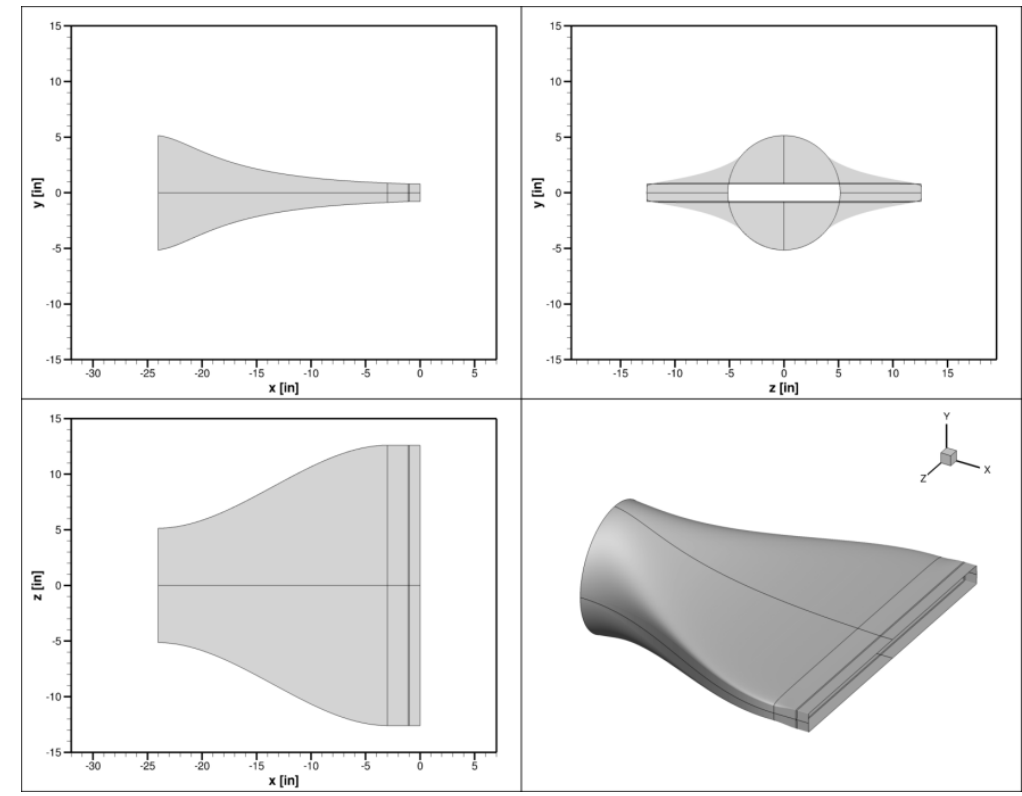

Figure 19: The A16.7 HAR nozzle design, generated using segmented approach.

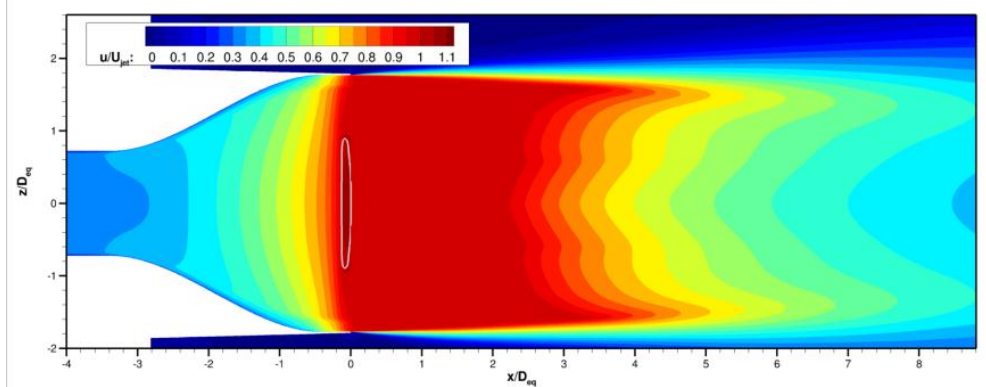

Figure 20: Contours of streamwise velocity along the $x-z$ symmetry plane of the A16.7 HAR nozzle design. Light gray contour line denotes $M=1$.

$$
\mathbf{W}^{*}\left(\mathrm{D}_{\mathrm{eq}} / \mathbf{U}_{\text {jet }}\right): 0 \begin{array}{llll}
0 & 10 & 20 & 3050
\end{array}
$$

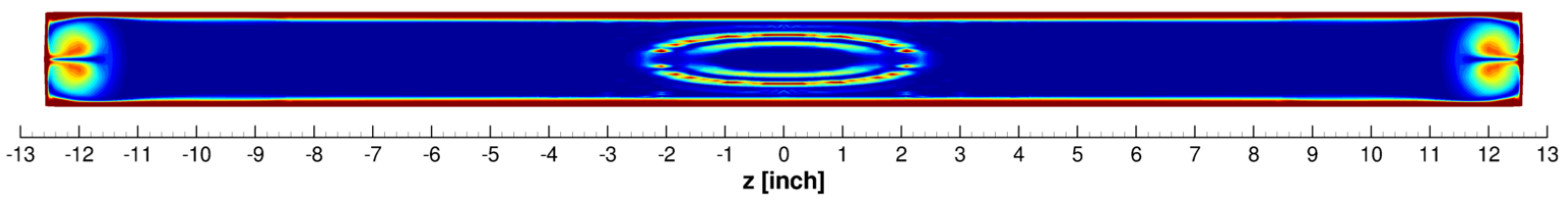

Figure 21: Contours of vorticity along x-stations inside the A16.7 HAR nozzle design. 


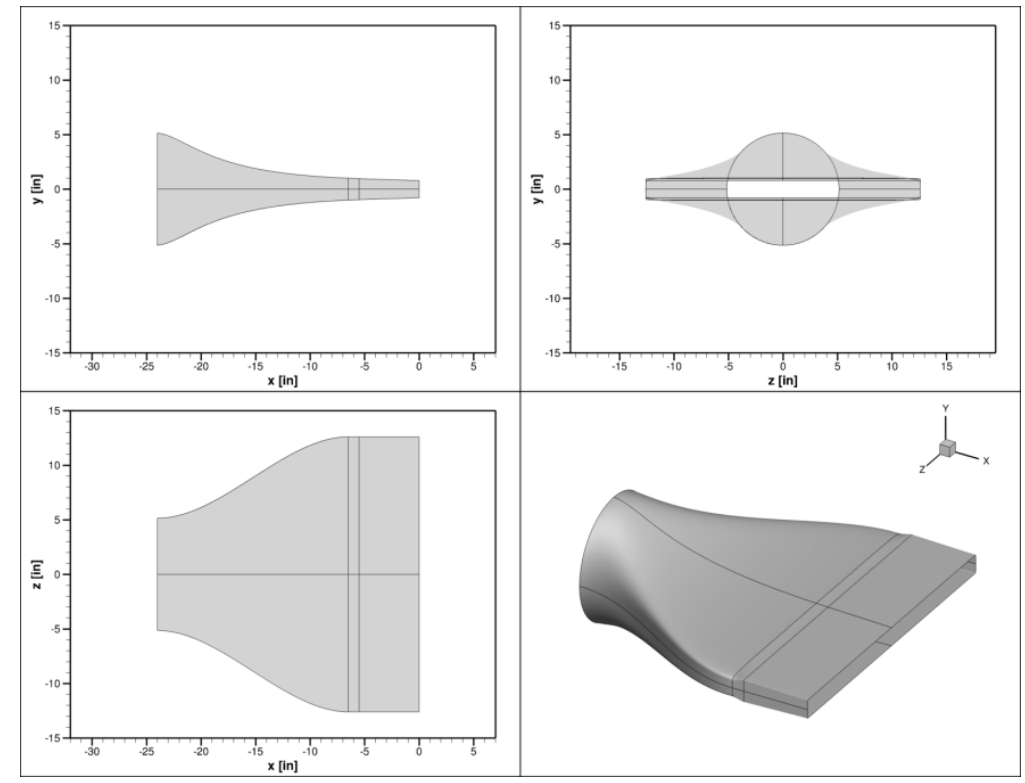

Figure 22: The A16.10 HAR nozzle design, generated using segmented approach.

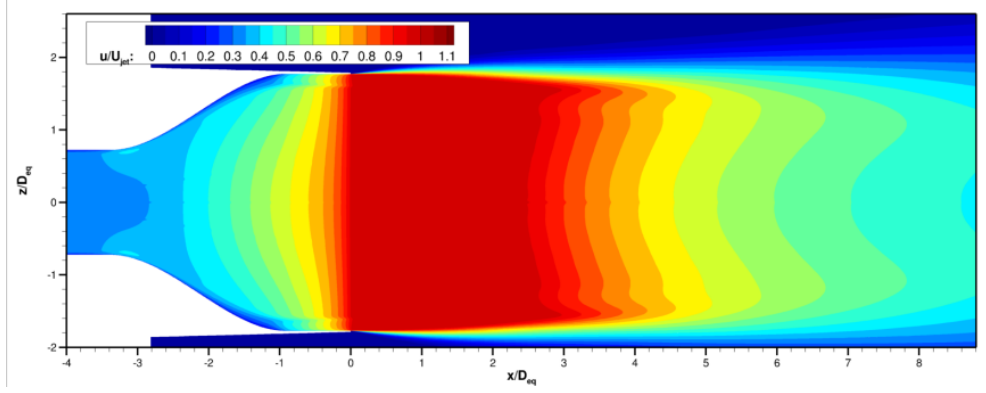

Figure 23: Contours of streamwise velocity along the $x-z$ symmetry plane of the A16.10 HAR nozzle design.

$$
\mathbf{W}^{\star}\left(\mathbf{D}_{\text {eq }} / \mathbf{U}_{\text {jet }}\right): 0 \quad 1020304050
$$

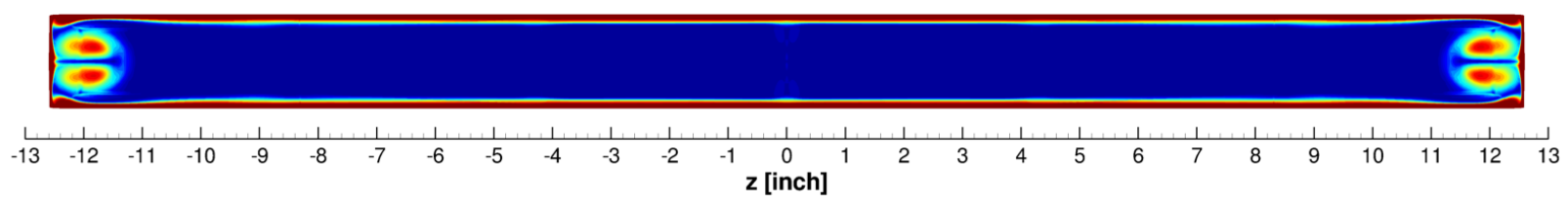

Figure 24: Contours of vorticity at the exit plane of the A16.10 HAR nozzle design. 


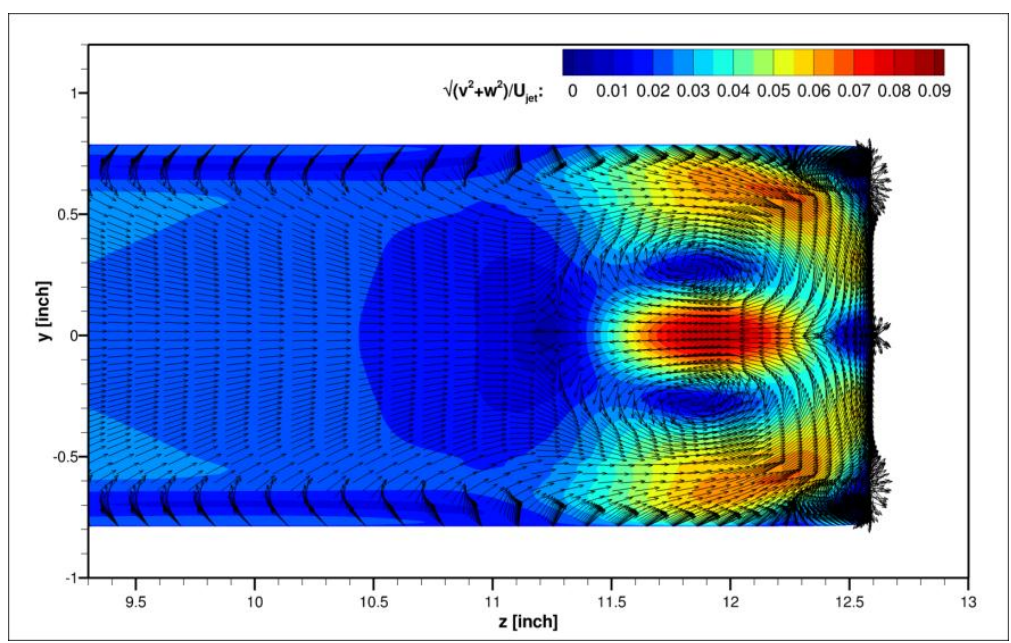

Figure 25: Plot of cross-stream velocity vectors at exit plane of the A16.10 HAR nozzle design.

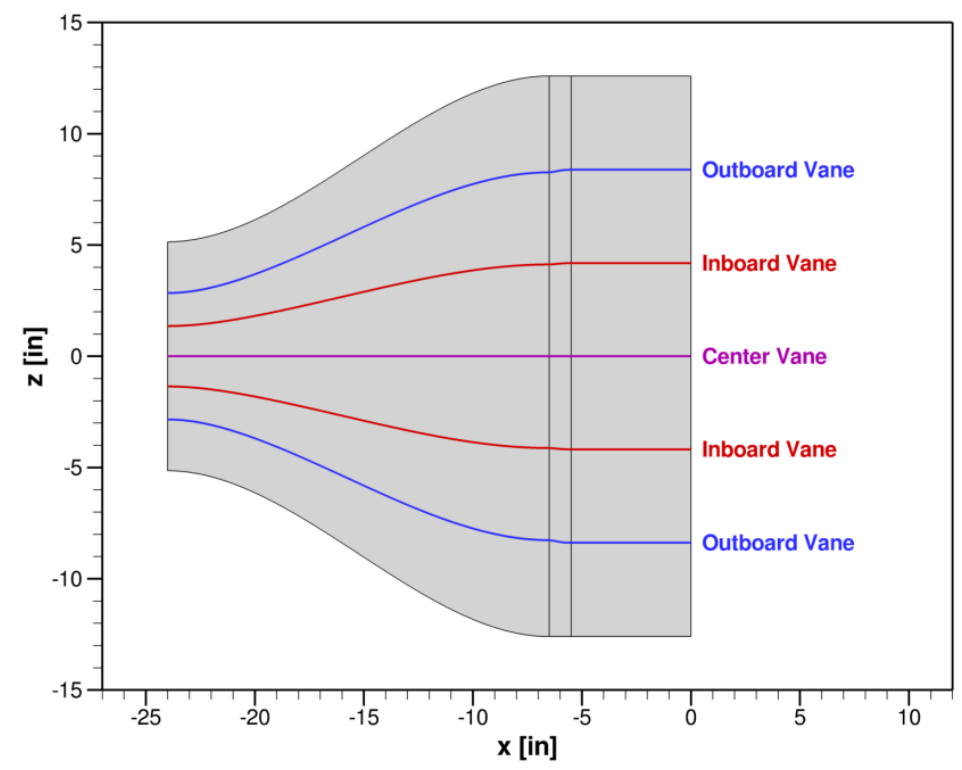

Figure 26: Curves showing locations of turning vanes for the A16.10 nozzle. The vane lines divide the nozzle's cross-sectional area into sixths. 


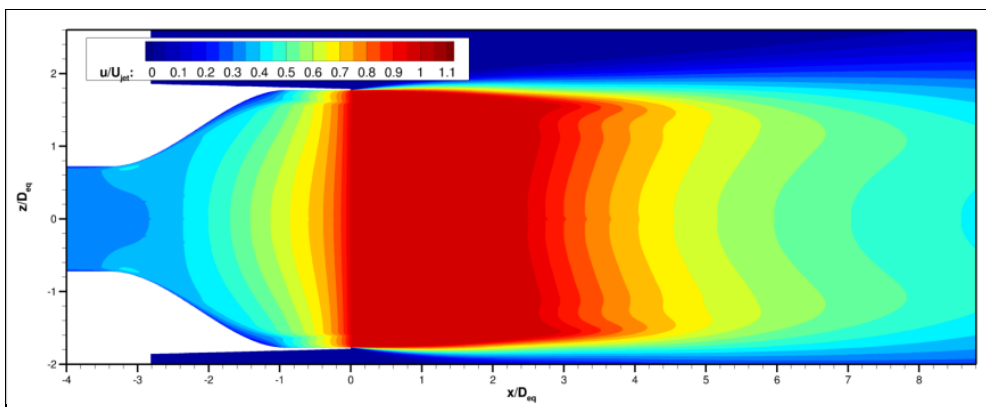

a) No vanes.

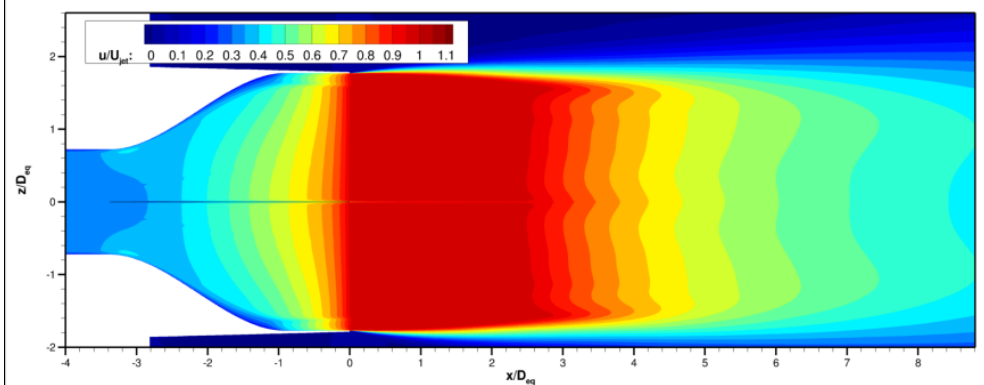

b) Center vane.

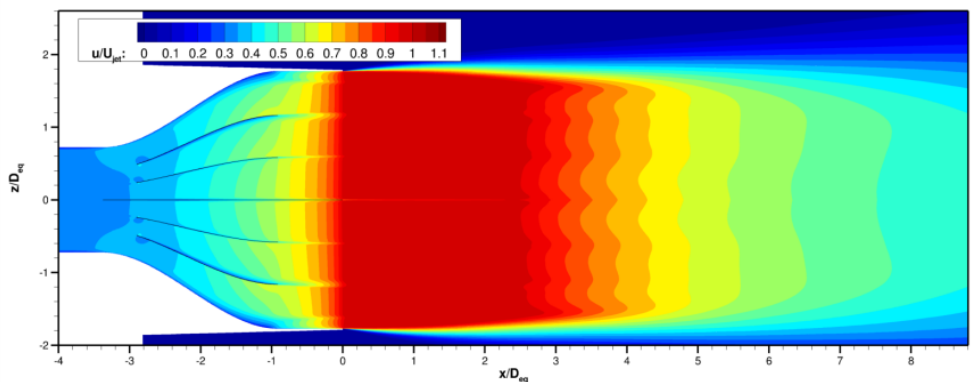

c) Turning vanes.

Figure 27: Contours of streamwise velocity along the $x-z$ symmetry plane of the A16.10 HAR nozzle designs with and without vanes. 


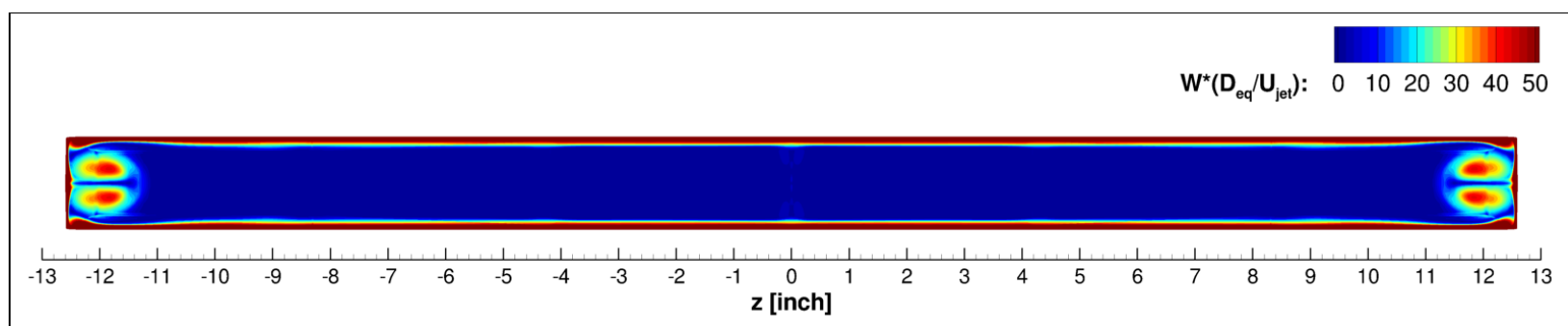

a) No vanes.

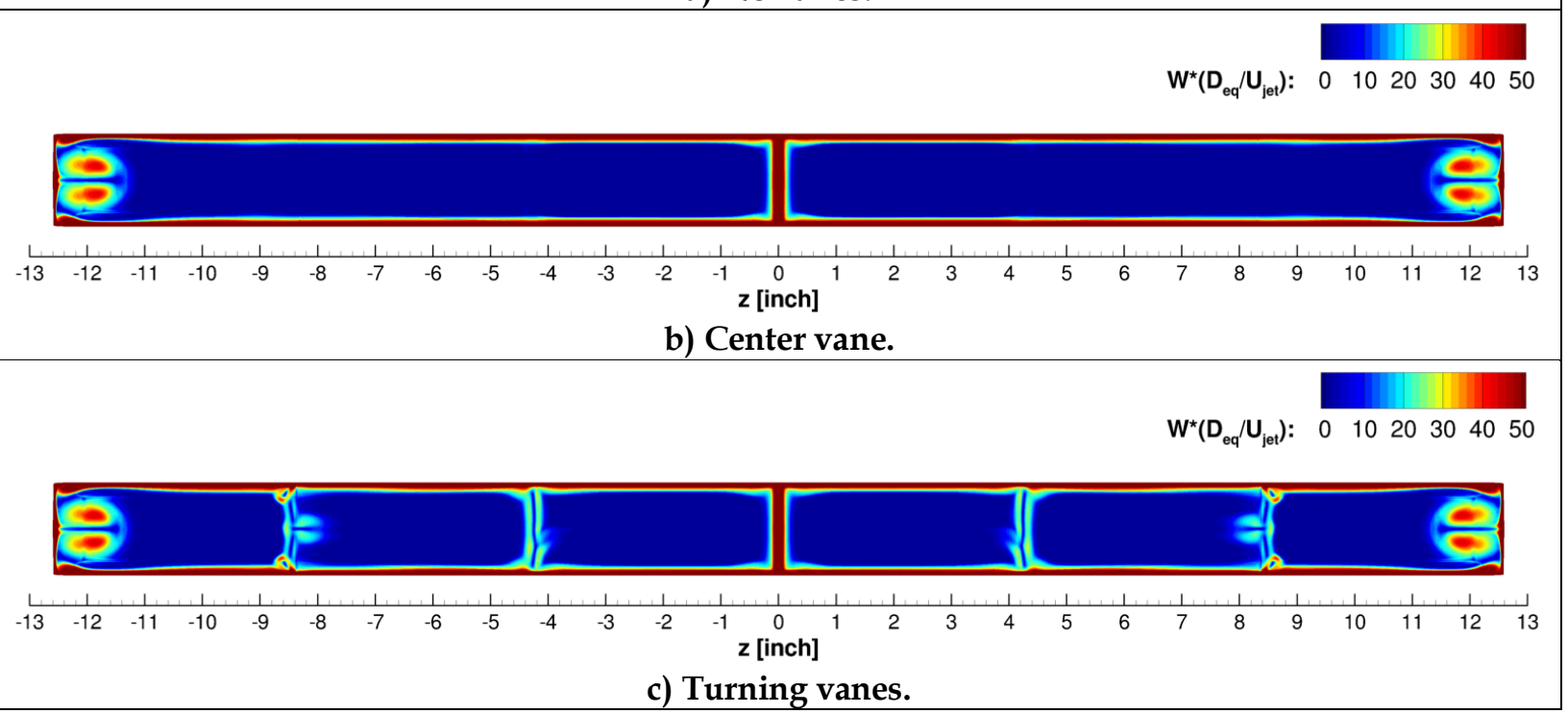

Figure 28: Contours of vorticity at the exit plane of the A16.10 HAR nozzle design.

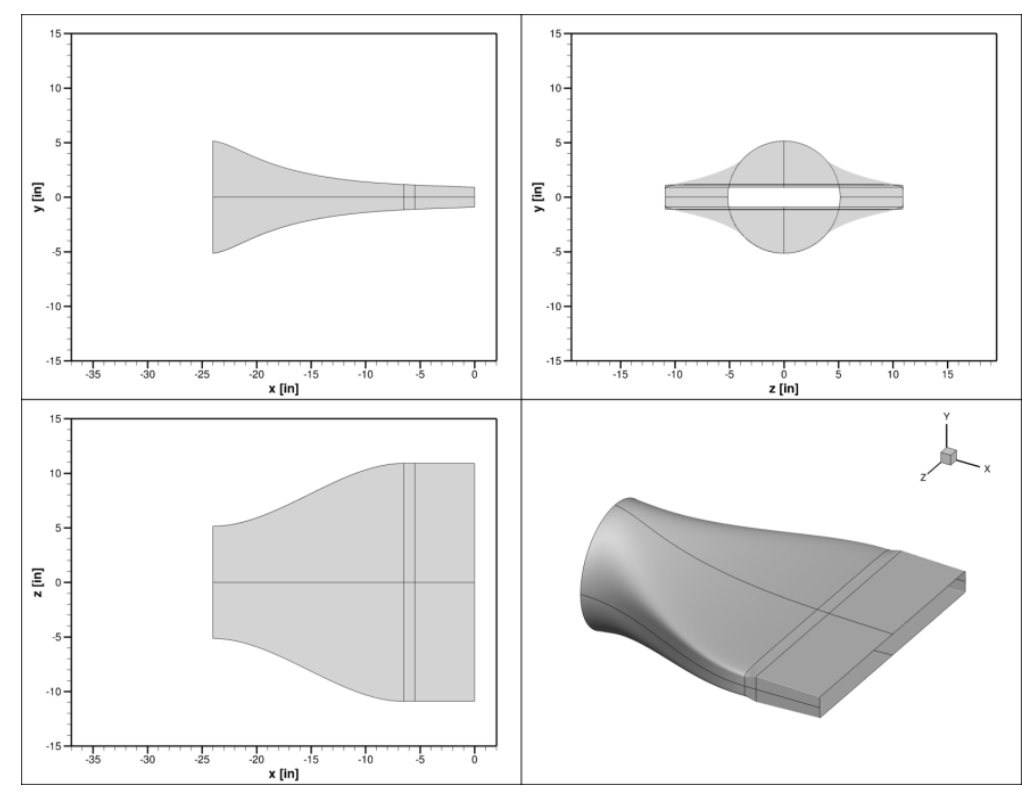

Figure 29: The A12.10 HAR nozzle design, generated using segmented approach. 


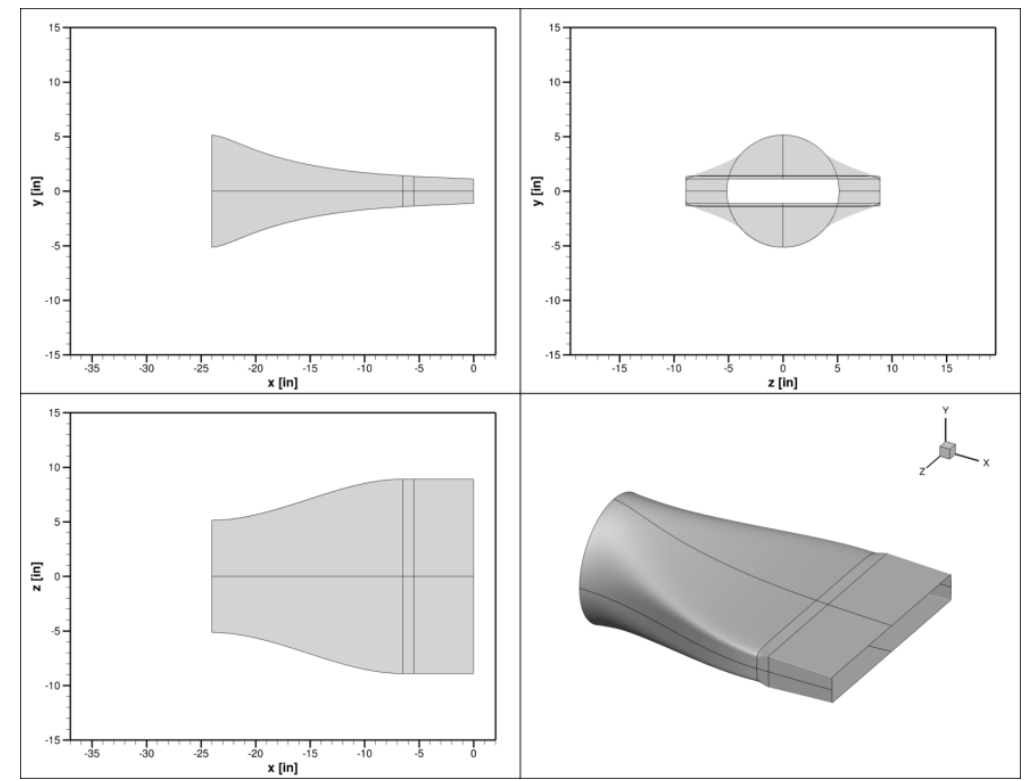

Figure 30: The A8.10 HAR nozzle design, generated using segmented approach.

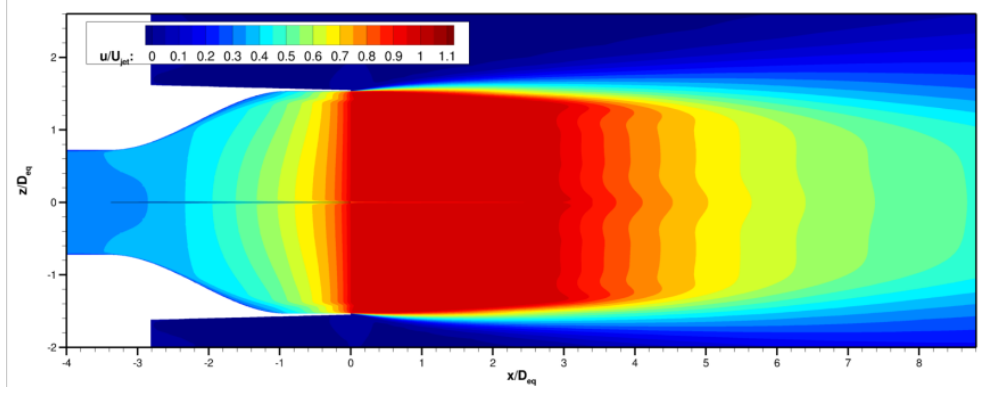

Figure 31: Contours of streamwise velocity along the $x-z$ symmetry plane of the A12.10 HAR nozzle design.

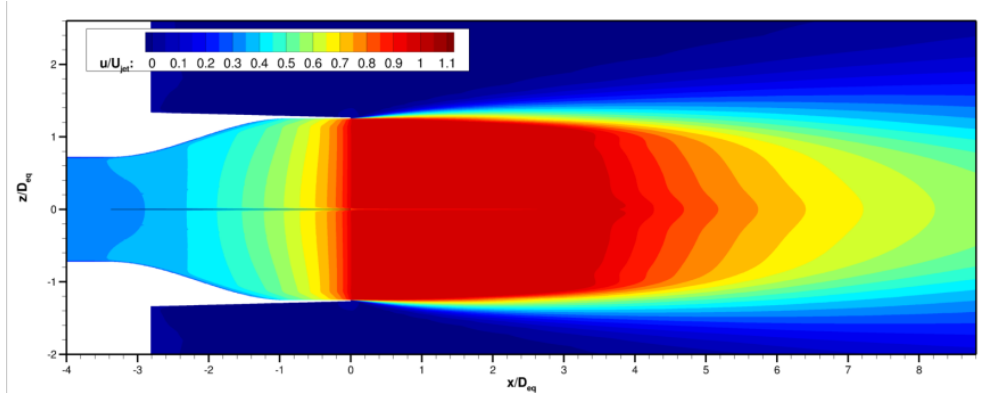

Figure 32: Contours of streamwise velocity along the $x-z$ symmetry plane of the A8.10 HAR nozzle design. 


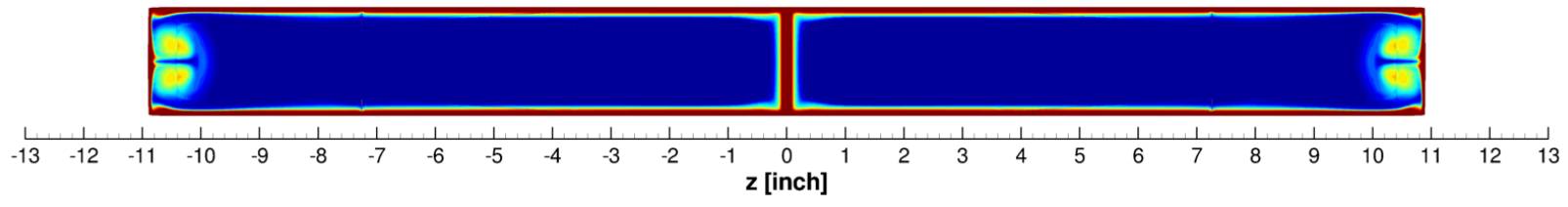

Figure 33: Contours of vorticity at the exit plane of the A12.10 HAR nozzle design.

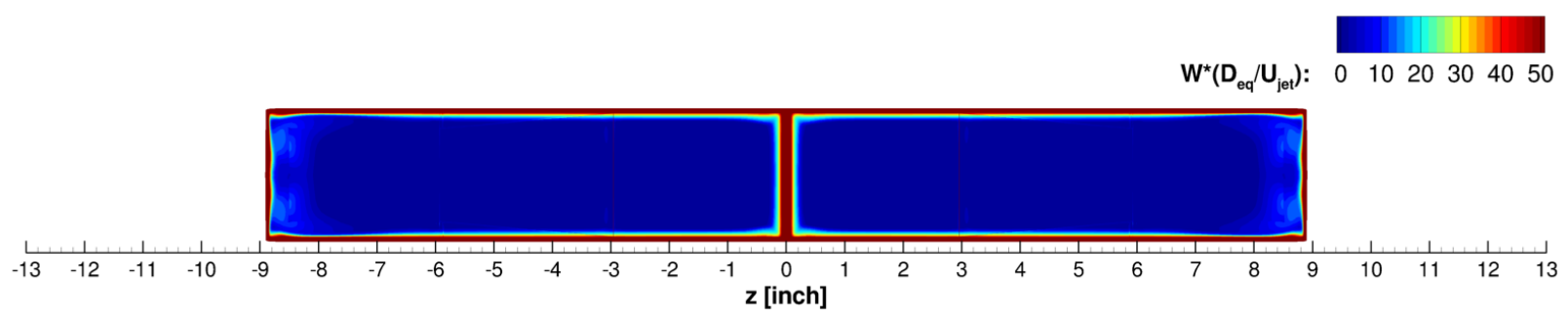

Figure 34: Contours of vorticity at the exit plane of the A8.10 HAR nozzle design.

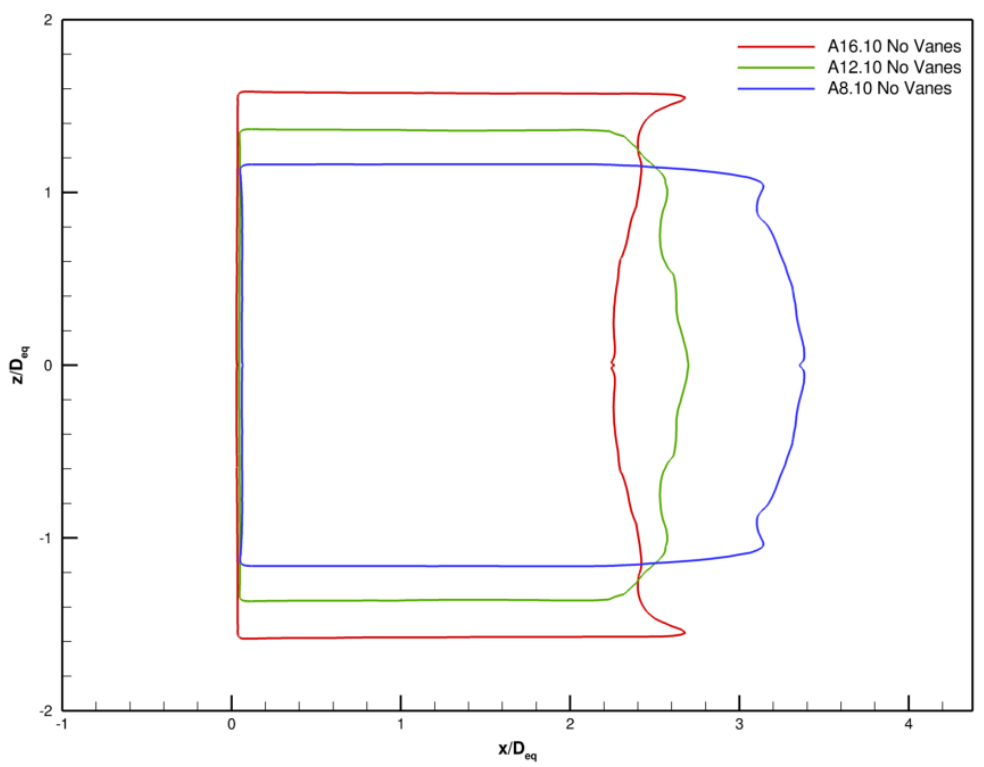

Figure 35: Comparison of the jet potential cores of HAR nozzles. Lines denote where $u=0.99 \times U_{j e t}$ for each HAR nozzle simulation. 